\title{
Agonist efficiency from concentration-response curves: structural implications and applications
}

Running title: agonist efficiency

D. C. Indurthi and A. Auerbach

Key words: nicotinic, acetylcholine receptor, dose-response, pharmacology

A preliminary version of this work [doi.org/10.1101/2020.10.13.337410] was deposited in bioRxiv on $10 / 14 / 2020$. 


\section{Abstract}

Agonists are evaluated by a concentration-response curve (CRC), with a midpoint $\left(\mathrm{EC}_{50}\right)$ that indicates potency, a high-concentration asymptote that indicates efficacy and a lowconcentration asymptote that indicates constitutive activity. A third agonist attribute, efficiency $(\eta)$, is the fraction of binding energy that is applied to the conformational change that activates the receptor. We show that $\eta$ can be calculated from $\mathrm{EC}_{50}$ and the asymptotes of a CRC derived from either single-channel or whole-cell responses. For 20 agonists of skeletal muscle nicotinic receptors, the distribution of $\eta$ values is bimodal with population means at 51\% (including ACh, nornicotine and DMPP) and 40\% (including epibatidine, varenicline and cytisine). The value of $\eta$ is related inversely to the size of the agonist's head-group, with high- versus low-efficiency ligands having an average volume of $70 \AA^{3}$ versus $102 \AA 3$. Most binding site mutations have only a small effect on ACh efficiency except for $\alpha Y_{190 A}(35 \%), \alpha \mathrm{W} 149 \mathrm{~A}(60 \%)$ and those at $\alpha \mathrm{G} 153$ (42\%). If $\eta$ is known, the midpoint and high-concentration asymptote can be calculated from each other. Hence, an entire CRC can be estimated from the response to a single agonist concentration, and efficacy can be estimated from $\mathrm{EC}_{50}$ of a $\mathrm{CRC}$ that has been normalized to 1 . Given $\eta$, the level of constitutive activity can be estimated from a single CRC. 


\section{Statement of significance}

Receptors are molecular machines that convert chemical energy from agonist binding into mechanical energy of a global conformational change that generates a cell response. Agonists are distinguished by their potency (proportional to affinity) and efficacy, but also by the efficiency at which their binding energy is applied to receptor activation. Here we show that agonist efficiency can be estimated from a single concentrationresponse curve, and estimate efficiencies of 20 nicotinic receptor agonists. These have a bimodal distribution with larger agonists belonging to the lower-efficiency population. We further show that mutations of some binding site residues alter efficiency, and that knowledge of agonist efficiency simplifies and extends dose-response curve analysis. 


\section{Introduction}

Nicotinic acetylcholine receptors (AChRs) are members of the cys-loop, ligandgated receptor family that in mammals also comprise $\mathrm{GABA}_{\mathrm{A}}$, glycine, $5-\mathrm{HT}_{3}$ and zincactivated receptors (1). They are 5-subunit, liganded-gated ion channels with agonist binding sites in the extracellular domain, far from a narrow region of the pore in the transmembrane domain that regulates ion conductance $(2,3)$.

AChRs switch between global C(losed-channel) and O(pen-channel) conformations ('gating') to produce transient membrane currents. Agonists promote channel opening because they bind more strongly to the O conformation. Importantly, the energy (structure) of the binding site at the gating transition state resembles that of $\mathrm{O}$ (4). Hence, when a receptor begins its journey from $\mathrm{C}$ to $\mathrm{O}$, extra (favorable) binding energy eases the pathway, thereby increasing the probability of reaching and residing in $\mathrm{O}\left(\mathrm{P}_{\mathrm{O}}\right)(5,6)$.

AChRs are the primary receptors at vertebrate neuromuscular synapses where they initiate muscle membrane depolarization and contraction. Neuromuscular AChRs have two $\alpha 1$ subunits and one each of $\beta, \delta$ and either $\varepsilon$ (adult) or $\gamma$ (fetal). There are two neurotransmitter binding-sites located at $\alpha 1-\delta$ and $\alpha 1-\varepsilon / \gamma$ subunit interfaces (7) that are approximately equivalent for ACh in adult-type AChRs (5). AChRs switch conformation spontaneously (only under the influence of temperature), with the presence of neurotransmitters at both adult sites increasing the opening rate constant by a factor of $\sim 5$ million and the lifetime of the $\mathrm{O}$ conformation by a factor of $\sim 5$.

Agonists are typically characterized by a potency (proportional to affinity) and an efficacy. Affinity is a measure of how strongly the ligand binds to its target site and is the inverse of an equilibrium dissociation constant. The constants $K_{d C}$ and $K_{d O}$ 
correspond to low-affinity (weak) binding to the $\mathrm{C}$ conformation and high-affinity (strong) binding to the $\mathrm{O}$ conformation. (The logarithm of an equilibrium dissociation constant is proportional to binding energy.)

The high-concentration asymptote of a $\mathrm{CRC}$, or the maximum response elicited by the ligand, is called $\mathrm{P}_{\mathrm{O}}$ max in single-channel or Imax in whole-cell currents. This limit gives the agonist's efficacy and depends only on the fully-liganded gating equilibrium constant. The midpoint of a $\mathrm{CRC}$, or the agonist concentration that produces a halfmaximal response is proportional to $\mathrm{K}_{\mathrm{dC}}$ but also depends on the gating equilibrium constant.

The low-concentration asymptote of a $\mathrm{CRC}$, which gives the level of activity in the absence of agonists ( $\mathrm{P}_{\mathrm{O}}{ }^{\mathrm{min}}$ or $\left.\mathrm{I}^{\mathrm{min}}\right)$, depends on the unliganded gating equilibrium constant that is typically small and difficult to measure. However, it is important to know the exact value of this constant because it multiplies the fully-liganded gating equilibrium constant to influence potency, efficacy and synaptic current profiles. Allosteric modulators and AChR mutations (8), including some that cause slow-channel myaesthenic syndromes (9), alter $\mathrm{EC}_{50}, \mathrm{I}^{\max }$ and the time course of synaptic currents simply by increasing or decreasing the unliganded gating equilibrium constant, without making a noticeable change in baseline activity.

Recently, efficiency ( $\eta$; eta) was defined as the fraction of an agonist's chemical binding energy that is converted into the mechanical (kinetic) energy for gating (10). Efficiency reports the strength of the link between binding and gating. As shown previously (and again below by using a different approach), $\eta$ is a function of the resting/active binding energy ratio, $\log \mathrm{K}_{\mathrm{dC}} / \log \mathrm{K}_{\mathrm{do}}$. Direct, independent measurements of these two equilibrium dissociation constants obtained by detailed kinetic modeling of 
single-channel currents indicated that at adult-type human AChR neurotransmitter binding sites, ACh and 3 related agonists on average apply $\sim 50 \%$ of their binding energy to gating whereas at the $\alpha 1-\delta$ binding site the frog toxin epibatidine and 3 related agonists on average apply only 40\% (10).

Here, we show that agonist efficiency can be estimated from the asymptotes and midpoint of a single CRC constructed from either single-channel or whole-cell responses. Given two agonists with the same $\mathrm{EC}_{50}$, the one with the larger $\mathrm{I}^{\max }$ has the greater $\eta$. We provide separate efficiency estimates for 20 agonists of mouse adult AChRs and show that knowledge of agonist efficiency broadens our understanding of receptor activation and drug action. 


\section{Materials and Methods}

\section{Experimental design}

Expression. Human embryonic kidney (HEK) 293 cells were maintained in Dulbecco's minimal essential medium supplemented with $10 \%$ fetal bovine serum and $1 \%$ penicillin-streptomycin, $\mathrm{pH}$ 7.4. For single-channel experiments, AChRs were expressed by transient transfection of $3 \mu \mathrm{g}$ mouse $\alpha 1, \beta, \delta$ and $\varepsilon$ subunits in the ratio 2:1:1:1 (TransIT $^{\circledR} 293$ transfection reagent; Mirus Bio, Madison, WI). Electrophysiological experiments started $\sim 48$ hours post-transfection. For whole cell recording, HEK-293 cells were transiently transfected with adult-type mouse AChRs using calcium phosphate precipitation. $20 \mu \mathrm{g}$ of $\mathrm{cDNA}$ was added in the ratio of 2:1:1:1 ( $\alpha 1$-GFP encoded between M3-M4, $\beta, \delta$ and $\varepsilon$ ) to a T75 flask at $\sim 60 \%$ confluence. Cells were incubated for $\sim 16 \mathrm{hr}$ at $37^{\circ} \mathrm{C}$, replenished with fresh medium and harvested after $\sim 20$ hrs of washing. GFP positive cells were sorted by using a ABD FACS Fusion 4 laser Cell Sorter (Becton Dickinson, Franklin Lakes, NJ). Cells were excited with laser at 488 $\mathrm{nm}$ and the GFP signal was collected in the green channel through a 530/40 filter. A light scatter gate was drawn in the SSC versus FS plot to exclude debris and to include viable single cells. No animals were used in this study.

Electrophysiology. Single-channel currents were recorded in the cell-attached patch configuration at $23^{\circ} \mathrm{C}$. The bath solution was (in $\mathrm{mM}$ ): $142 \mathrm{KCl}, 5.4 \mathrm{NaCl}, 1.8 \mathrm{CaCl}_{2}, 1.7$ $\mathrm{MgCl}_{2}, 10 \mathrm{HEPES} / \mathrm{KOH}$ ( $\mathrm{pH}$ 7.4). Patch pipettes were fabricated from borosilicate glass and fire polished to a resistance of $\sim 10 \mathrm{M} \Omega$ when filled with the pipette solution that was Dulbecco's phosphate-buffered saline (in $\mathrm{mM}$ ): $137 \mathrm{NaCl}$, $0.9 \mathrm{CaCl}_{2}, 2.7 \mathrm{KCl}, 1.5$ $\mathrm{KH}_{2} \mathrm{PO}_{4}, 0.5 \mathrm{MgCl}_{2}$, and $8.1 \mathrm{Na}_{2} \mathrm{HPO}_{4}(\mathrm{pH} 7.3 / \mathrm{NaOH})$. Currents were recorded using a 
PC505 amplifier (Warner instruments, Hamden, CT), low-pass filtered at $20 \mathrm{kHz}$ and digitized at a sampling frequency of $50 \mathrm{kHz}$ using a data acquisition board (SCB-68, National instruments, Austin, TX). Agonists were added to the pipette solution at the desired concentration.

Whole-cell currents were recorded using an IonFlux 16 automated patch-clamp system (Fluxion, California, USA) on 96-well IonFlux microfluidic ensemble plates that give a cumulative whole-cell current from up to 20 cells. GFP-positive cells were resuspended in extracellular solution containing (in mM): $138 \mathrm{NaCl}, 4 \mathrm{KCl}, 1.8 \mathrm{CaCl}_{2}, 1$ $\mathrm{MgCl}_{2}, 5.6$ glucose and 10 HEPES, pH adjusted to 7.4 with $\mathrm{NaOH}$. Cells were captured in the trapping wells with intracellular solution containing $60 \mathrm{KCl}, 7 \mathrm{O} \mathrm{KF}, 15 \mathrm{NaCl}, 5$ HEPES and 5 EGTA, pH adjusted to 7.2 using KOH. Cells clamped at $-80 \mathrm{mV}$ were exposed to a $2 \mathrm{~s}$ agonist application followed by $90 \mathrm{~s}$ wash between applications to allow recovery from desensitization. IonFlux software (ver.4.5) was used for cell capture, seal formation, compound application and data acquisition.

Analysis. Scheme 1 (Fig. 1) shows the main states of AChR activation/de-activation. First, we estimated $\eta$ from single-channel current CRCs. When agonist-binding and channel-opening rate constants are sufficiently large, openings occur in clusters (11) (Fig. 2A, Fig. S1-S4). Shut intervals within clusters represent mainly agonist binding to $\mathrm{C}$ and channel opening (bold in Fig. 1), whereas shut intervals between clusters represent mainly long-lived desensitization (not shown in Fig. 1; for connections see (6)). We selected for analysis clusters that appeared by eye to arise from a homogeneous $\mathrm{P}_{\mathrm{O}}$ population and, in order to exclude sojourns in desensitized states, limited our analyses to intra-cluster interval durations. 
Because of the high extracellular $\left[\mathrm{K}^{+}\right]$, the cell membrane potential $\left(\mathrm{V}_{\mathrm{m}}\right)$ was $\mathrm{O}$ $\mathrm{mV}$. The AChR agonists we examined also are channel-blockers. To both generate measurable currents and reduce the effect of channel block on $\mathrm{P}_{\mathrm{O}}$, the membrane was depolarized to $+70 \mathrm{mV}$ by holding the pipette at $-70 \mathrm{mV}$. This effectively eliminated agonist binding to the channel-block site in the transmembrane domain but did not affect agonist binding to the neurotransmitter sites in the extracellular domain.

Analyses of the single-channel (outward) currents were performed by using QUB software (12). A cluster was defined as a group of openings flanked by shut intervals longer than a duration that depended on the agonist concentration (range, 7-20 ms). Open and shut currents within clusters were idealized into noise-free intervals by using the segmental k-means algorithm after digitally low-pass filtering the data at $10 \mathrm{kHz}$ (13). Idealized interval durations were fitted by multiple exponential components using a maximum interval likelihood algorithm (14). Cluster $\mathrm{P}_{\mathrm{O}}$ at each agonist concentration was calculated from the time constants of the predominant components of the shut- $\left(\tau_{\mathrm{s}}\right)$ and open-time distributions $\left(\tau_{\circ}\right): \tau_{\circ} /\left(\tau_{\mathrm{s}}+\tau_{\mathrm{o}}\right)$ (Fig. $\left.2 \mathrm{~B}\right)$. The single-channel CRC was a plot of the absolute $\mathrm{P}_{\mathrm{O}}$ (not normalized) versus the agonist concentration.

We also estimated $\eta$ from whole-cell current CRCs. The currents were digitized using a sampling frequency of $10 \square \mathrm{kHz}$ and were analyzed using IonFlux Data Analyzer v5.O. Peak currents were normalized to a maximum response (I/Imax), where Imax was the response to $300 \mu \mathrm{M}$ ACh. The $20-80 \%$ rise time to a step to $300 \mu \mathrm{M}$ ACh was $\sim 400$ ms, a time we attribute to solution exchange.

The rate of entering a long-lived desensitized state is proportional to cluster $\mathrm{P}_{\mathrm{O}}$ and occurs with a rate constant of $\sim 5 \mathrm{~S}^{-1}(15)$. Hence, under conditions where $\mathrm{P}_{\mathrm{O}}$ is $\sim 1$, a 
whole-cell current will decline with a time constant of $\sim 200 \mathrm{~ms}$. As a consequence, the peaks of whole-cell currents elicited by high-concentrations of high-efficacy agonists are truncated because of the solution exchange time. This has the effect of shifting $\mathrm{EC}_{50}$ to lower concentrations. Responses at lower agonist concentrations or from lower-efficacy agonists were unaffected by desensitization.

Voltage, $\underline{E}_{\underline{o}}$ and background mutations. Depolarization to $\mathrm{V}_{\mathrm{m}}=+70 \mathrm{mV}$ reduces channel block by the agonist but has the undesired consequence of shortening $\tau_{\mathrm{o}}$ to make singlechannel current detection and idealization difficult. To compensate, we added the background mutation $\varepsilon S 450 W$ (in the M4 transmembrane segment of the $\varepsilon$ subunit) that has the equal-but-opposite effect on the unliganded gating equilibrium constant $\mathrm{E}_{\mathrm{O}}$ as does depolarization by $+140 \mathrm{mV}$, but has no effect on agonist binding (16). With this mutation, $\tau_{\mathrm{o}}$ and $\mathrm{E}_{\mathrm{o}}$ at $+70 \mathrm{mV}$ were the same as in wild-type (wt) adult $\mathrm{AChRs}$ at $\mathrm{V}_{\mathrm{m}}=-$ $70 \mathrm{mV} . \mathrm{E}_{\mathrm{o}}$ at $-100 \mathrm{mV}$ is $7.4 \times 10^{-7}$ and is reduced e-fold by a $60 \mathrm{mV}$ depolarization (17). Hence, we estimate that in our experiments at $\mathrm{V}_{\mathrm{m}}=+7 \mathrm{O} \mathrm{mV}$ and with $\varepsilon S 450 \mathrm{~W}, \mathrm{E}_{\mathrm{o}}$ was 5.2 $\mathrm{x} 10^{-7}$. In the whole-cell experiments, no background mutations were used and $\mathrm{V}_{\mathrm{m}}=-80$ $\mathrm{mV}$, so we estimate $\mathrm{E}_{\mathrm{o}}$ was $5 \cdot 9 \times 10^{-7}$.

With the low-efficacy agonists varenicline, tetraethylammonium and tetramethylphosphonium, single-channel clusters generated by wt AChRs were poorly defined because the channel-opening rate constant was small. For these ligands, $\mathrm{P}_{\mathrm{O}}$ could not be estimated accurately using wt AChRs. To increase the diliganded opening rate constant and generate better-defined, higher- $\mathrm{P}_{\mathrm{O}}$ clusters, we added two background mutations in the $\varepsilon$ subunit, $\varepsilon \mathrm{L} 269 \mathrm{~F}$ (in the M2 helix) and $\varepsilon \mathrm{E} 181 \mathrm{~W}$ (in strand $\beta 9$ ), without 
ES450W. Together, these two substitutions increase $\mathrm{E}_{\mathrm{o}}$ by 1084 -fold (making it $4.9 \times 10^{-4}$ ) without affecting agonist binding $(18,19)$. From the uncorrected CRC, we estimated an $\mathrm{E}_{2}$ value from the $\mathrm{P}_{\mathrm{O}}^{\max }(\mathrm{Eq} .4)$ and $\mathrm{K}_{\mathrm{dC}}$ from $\mathrm{EC}_{50}$. We divided this $\mathrm{E}_{2}$ by 1084 to arrive at a corrected $\mathrm{E}_{2}$ from which we calculated corrected $\mathrm{P}_{\mathrm{O}}$ max and $\mathrm{EC}_{5 \mathrm{o}}$ values that pertain to wt AChRs (Table 1).

Equations. Single-channel CRCs were constructed from $\mathrm{P}_{\mathrm{O}}$ values after eliminating extraneous events arising from channel block, desensitization and modal activity (20). Whole-cell CRCs were constructed directly from peak currents. $\mathrm{EC}_{50}$ and $\mathrm{P}_{\mathrm{O}}{ }^{\max }$ (or Imax) the Hill coefficient $\left(\mathrm{n}_{\mathrm{H}}\right)$ were estimating by fitting the $\mathrm{CRC}$,

$$
P_{O}=\frac{P_{O}^{\max }}{1+\left(\frac{E C_{50}}{[\text { agonist }]}\right)^{n_{H}}} \quad \text { Eq. } 1
$$

Scheme 1 (Fig. 1) was used to derive expressions for $\eta$. Because microscopic reversibility is satisfied,

$$
\frac{E_{2}}{E_{0}}=\left(\frac{K_{d C}}{K_{d O}}\right)^{2}
$$

$\mathrm{E}_{2}$ and $\mathrm{E}_{\mathrm{o}}$ are the diliganded and unliganded gating equilibrium constants and $\mathrm{K}_{\mathrm{dc}}$ and $\mathrm{K}_{\mathrm{do}}$ are the equilibrium dissociation constants for binding to $\mathrm{C}$ and $\mathrm{O}$. The exponent reflects the fact that in adult-type AChRs there are 2 neurotransmitter sites that are approximately equivalent and independent with regards to the agonists used in this study. Eq. 2 has been confirmed by experiment (5).

Constitutive and mono-liganded activity are both rare, so in wt AChRs the only significant pathway that generates current is the clockwise, linear activation route 
highlighted in Fig. 1. Transitions between these 4 states determine $\mathrm{P}_{\mathrm{O}}$ and, hence, the experimental values of $\mathrm{EC}_{50}$ and $\mathrm{P}_{\mathrm{O}}$ max (or Imax).

Accordingly, $\mathrm{EC}_{5 \mathrm{o}}$ depends on both binding and gating equilibrium constants,

$$
E C_{50}=\frac{K_{d C} \sqrt{E_{2}+2}}{E_{2}+1} \quad \text { Eq. } 3
$$

whereas $\mathrm{P}_{\mathrm{O}}^{\max }\left(\mathrm{I}^{\mathrm{max}}\right)$ depends only on the gating equilibrium constant,

$$
P_{O}^{\max }=\frac{E_{2}}{E_{2}+1}
$$

This equation also can be used to relate $\mathrm{P}_{\mathrm{O}} \min \left(\mathrm{I}^{\min }\right)$ and $\mathrm{E}_{\mathrm{O}}$.

Agonist efficacy depends on the diliganded gating equilibrium constant that from Eq. 2 is a function of the affinity ratio, $\mathrm{K}_{\mathrm{dC}} / \mathrm{K}_{\mathrm{dO}}$. Taking the $\log$ of Eq. 2 , we see that efficacy is determined by the difference between the binding energies, $\log \left(\mathrm{K}_{\mathrm{dC}}\right)-\log \left(\mathrm{K}_{\mathrm{do}}\right)$. Partial agonists experience smaller increases in $\mathrm{O}$ versus $\mathrm{C}$ binding energy compared to full agonists, antagonists experience no change in binding energy, and inverse agonists experience a decrease in favorable binding energy upon receptor activation.

In contrast, $\eta$ depends on the ratio of these binding energies, $\log \left(\mathrm{K}_{\mathrm{dC}}\right) / \log \left(\mathrm{K}_{\mathrm{dO}}\right)$, as shown previously (10) and as follows. Agonist activation of a resting, unliganded AChR entails connecting the resting-unliganded state $\mathrm{C}$ to the diliganded-active state $\mathrm{A}_{2} \mathrm{O}$ (Fig. 1). The product of the equilibrium constants (or sum of the energy changes) for steps linking these states in the clockwise direction (the highlighted, physiological activation route) is the same as in the rarely-taken, counter-clockwise direction. The product of the counter-clockwise constants is $\mathrm{E}_{\mathrm{o}} / \mathrm{K}_{\mathrm{dO}}{ }^{2}$, the negative log of which is proportional to the total energy required for constitutive gating and binding to $\mathrm{O}$ at 2 sites, $2 \log \left(\mathrm{K}_{\mathrm{dO}}\right)-\log \mathrm{E}_{\mathrm{o}}$. The product of the equilibrium dissociation constants connecting 
C with $\mathrm{A}_{2} \mathrm{C}$ is $1 / \mathrm{K}_{\mathrm{dc}}{ }^{2}$, the negative $\log$ of which is proportional to the energy for just the binding part of clockwise activation, $2 \log \left(\mathrm{K}_{\mathrm{dc}}\right)$. We are interested only in the agonist component of the total energy and, because $\mathrm{E}_{\mathrm{o}}$ is agonist-independent, it can be ignored. Hence, the fraction of the total agonist energy that is used in binding is $2 \log \mathrm{K}_{\mathrm{dC}} / 2 \log \mathrm{K}_{\mathrm{dO}}$ so efficiency, or the fraction of this total that is applied to gating, is

$$
\eta=1-\frac{\log K_{d C}}{\log K_{d 0}} \quad \text { Eq. } 5
$$

Efficacy and efficiency are distinct, but related, agonist attributes. In terms of energy, efficiency is equal to efficacy $\left(\log \mathrm{K}_{\mathrm{do}}-\log \mathrm{K}_{\mathrm{dC}}\right)$ divided by $\log \mathrm{K}_{\mathrm{do}}$ (Eq. 5). An agonist can be high efficacy and low efficiency (epibatidine) or low efficacy and high efficiency (choline), but within limits. If an agonist has $\mathrm{P}_{\mathrm{O}}{ }^{\max }=0.75$ (about the same as TMA) and $\eta=30 \%$ it would have unreasonably small equilibrium dissociation constants, $\mathrm{K}_{\mathrm{dC}}=27 \mathrm{nM}$ and $\mathrm{K}_{\mathrm{dO}}=15 \mathrm{pM}$. In practice, high-efficacy agonists will also have high efficiencies.

Except for Fig 8A, we calculated efficiency from $\mathrm{EC}_{50}, \mathrm{P}_{0}{ }^{\max }$ and $\mathrm{P}_{0}{ }^{\min }$ using a stepwise approach: i) $\mathrm{E}_{2}$ from $\mathrm{P}_{0} \max \left(\mathrm{Eq} .4\right.$ ), ii) $\mathrm{K}_{\mathrm{dc}}$ from $\mathrm{E}_{2}$ and $\mathrm{EC}_{50}$ (Eq. 3), iii) $\mathrm{K}_{\mathrm{dO}}$ from $E_{2}$ and $K_{d C}$ using a known value of $E_{o}$ (Eq. 2), and, finally, iv) $\eta$ from the equilibrium dissociation constant ratio (Eq. 5). In Fig. 8A only, an approximate value of $\eta$ was calculated directly using Eq. 10 with $\mathrm{A}=0$.

Four prior results enabled us to estimate $\eta$ from a CRC. First, adult AChR binding sites have approximately the same affinity, so only single values of the equilibrium dissociation constants needed to be estimated for each ligand. Second, Scheme 1 and microscopic reversibility have been proved experimentally. Third, the unliganded gating equilibrium constant has been measured. In an 'efficiency' plot for a 
group of ligands (10), $\mathrm{E}_{\mathrm{o}}$ is estimated from the $\mathrm{y}$-intercept (see Eq. 8, below). However, prior knowledge of $\mathrm{I}^{\mathrm{min}}\left(\sim \mathrm{E}_{\mathrm{o}}\right)$ is required to estimate efficiency from a single CRC. Imin is the same for all agonists and so needs to be estimated only once for each receptor (at a given membrane potential).

Statistical analyses. For both single-channel and whole-cell CRCs, the midpoint, maximum and slope $\left(\mathrm{EC}_{5 \mathrm{O}}, \mathrm{P}_{\mathrm{O}}^{\max }\right.$ or Imax , and $\left.\mathrm{n}_{\mathrm{H}}\right)$ were estimated by fitting by Eq. 1 using GraphPad Prism 6 (GraphPad Inc., San Diego, CA). Eq. 9 was solved numerically for E 2 using the symbolic math program Wolfram Alpha.

The goodness of fit for the efficiency frequency distribution (Fig. 5A) was estimated using Prism. The F-test rejects the null hypothesis (Gaussian fit) over sum of two Gaussian with an $\mathrm{F}$-value $(\mathrm{F}=3.9)$ and significance (P-value, <0.05). A k-means cluster analysis algorithm (MATLAB ${ }^{\circledR}$, MathWorks, Natick, MA) was used to define agonist groups for 2D cluster analysis, both efficiency and head-group volume (Fig. 5B). Correlation significance between $\log \mathrm{EC}_{50}$ or $\log \mathrm{P}_{\mathrm{O}}$ max , measured from CRCs or calculated from each other (Fig. 8A) was by Pearson's correlation test, using Prism software. The P-value (two-tail) $<0.0001$ and $\mathrm{r}^{2}=0.78$ or 0.74 imply that there is a significant correlation.

Agonists. Agonist structures are shown in Fig. 3, Fig. 4 and Fig. S5. Agonist head-group volumes (Fig. 5B) were calculated using Chimera (21). Acetylcholine (ACh), nornicotine (Nor), nicoztinc (Nic), carbamylcholine (CCh), anabasine (Ana), tetramethylammonium (TMA), dimethylthiazolidinium (DMT), dimethylpyrrolidium (DMP), choline (Cho), 3hydroxypropyltrimethylammonium (3OH-PTMA), 4-hydroxybutyltrimethylammonium 
(4OH-BTMA), anatoxin (Atx), azabicycloheptane (Aza), tetraethylammonium (TEA), epibatidine (Ebt), epiboxidine (Ebx), varenicline (Var), cytisine (Cyt), dimethylphenylpiperazinium (DMPP), tetramethylphosphonium (TMP). Cyt, Var, TEA and TMP were from Sigma ${ }^{\circledR}$ (St. Louis, MO). The sources for other agonists are given in previous publications $(10,22)$. 


\section{Results}

\section{ACh efficiency}

Fig. 2 shows example single-channel currents and CRCs. For the neurotransmitter $\mathrm{ACh}, \mathrm{P}_{\mathrm{O}}$ max and $\mathrm{EC}_{50}$ estimated by fitting the CRC by Eq. 1 are 0.96 and $43 \mu \mathrm{M}$ (Table 1). From $\mathrm{P}_{\mathrm{O}}^{\max }$ we calculate the diliganded gating equilibrium constant, $\mathrm{E}_{2}=23.4$ (Eq. 4). From this value and $\mathrm{EC}_{50}$ we calculate the low-affinity equilibrium dissociation constant, $\mathrm{K}_{\mathrm{dc}}=174 \mu \mathrm{M}$ (Eq. 3). The unliganded gating equilibrium constant at $+70 \mathrm{mV}$ is $5.2 \times 10^{-7}$ (see Methods) so we calculate the highaffinity equilibrium dissociation constant is $\mathrm{K}_{\mathrm{dO}}=26 \mathrm{nM}$ (Eq. 2). Finally, from the ratio of the logs of the two equilibrium dissociation constants we calculate the efficiency of the neurotransmitter, $\eta_{\mathrm{ACh}}=50 \%$ (Eq. 5).

We also calculated $\eta_{\mathrm{ACh}}$ from published values of $\mathrm{K}_{\mathrm{dC}}$ and $\mathrm{K}_{\mathrm{dO}}$ obtained either from wild-type mouse AChRs (23) or from individual $\alpha-\delta$ and $\alpha-\varepsilon$ human AChR binding sites (5), in both instances estimated by kinetic modeling of single-channel currents. The efficiencies calculated from these independent datasets are both 50\% (Table 1).

At adult AChR binding sites, half of the neurotransmitter binding energy is applied to the gating conformational change. That is, at each of the 2 binding sites the energy change when $\mathrm{ACh}$ binds to the $\mathrm{C}$ conformation is approximately equal to the increase in binding energy that happens within the C-to-O transition.

\section{Efficiency of other agonists}

We fitted other previously-published, single-channel CRCs (23) to estimate $\mathrm{EC}_{50}$ and $\mathrm{P}_{\mathrm{O}}$ max, and from these calculated agonist $\eta$ values as described above (Fig. 3 and Table 1). Despite the wide ranges in both $\mathrm{EC}_{50}(43 \mu \mathrm{M}$ to $6.7 \mathrm{mM})$ and $\mathrm{P}_{\mathrm{O}}$ max $(0.26$ to 
o.96), all 8 of these agonists (including ACh) have a similar efficiency, $\eta=52 \pm 2 \%$ (mean+s.d.) (Fig. 3B). The efficiency of the lowest-efficacy agonist in this group, DMP, was greater than that of the highest-efficacy agonist, ACh. This highlights the distinction between efficiency (that depends on the binding energy ratio) and efficacy (that depends on the binding energy difference).

Next, we measured efficiencies for agonists that were not studied previously by CRCs (Fig. 4). Choline (Cho) has 2 methylenes between its quaternary nitrogen and hydroxyl $(\mathrm{OH})$ group versus 3 and 4 for $3 \mathrm{OH}-\mathrm{BTMA}$ and $4 \mathrm{OH}-\mathrm{PTMA}$. Cho is a lowaffinity, low-efficacy agonist (24) that $\mathrm{K}_{\mathrm{dC}}$ and $\mathrm{K}_{\mathrm{do}}$ values estimated by modeling singlechannel kinetics at the human $\alpha-\varepsilon$ site indicate has a similar efficiency as does ACh (10). Simulations of binding site structures suggest that an $\mathrm{H}$-bond between the terminal $\mathrm{OH}$ and the backbone carbonyl of $\alpha \mathrm{W} 149$ serves to position the charged nitrogen of choline away from the aromatic rings that line the cavity, to reduce favorable binding energy $(25,26)$. Inserting additional methylenes reduces the probability of this $\mathrm{H}$-bond and allows a more-optimal position that increases binding energy relative to Cho.

The CRCs and associated $\mathrm{P}_{\mathrm{O}}$ max and $\mathrm{EC}_{50}$ values for $3 \mathrm{OH}-\mathrm{BTMA}$ and 4OH-PTMA are shown in Fig. 4A left. From the calculated equilibrium dissociation constants, we estimate $\eta$ is $50 \%$ for both agonists (Table 1 ). Despite the substantial range in affinity and efficacy afforded by the different H-bond propensities, all three of the choline agonists have the same efficiency that is similar to the efficiencies of the agonists shown in Fig. 3. The similarity in the $\mathrm{C}$ versus $\mathrm{O}$ binding energy ratio (but not the difference) for these 3 ligands suggests that the effect of the H-bond on the position of the nitrogen atom applies equally to $\mathrm{C}$ and $\mathrm{O}$ binding cavities. 
Fig. 4A left also shows the CRC of dimethylphenylpiperazinium (DMPP), a nicotinic receptor agonist that is selective for the $\alpha 3 \beta 4$ (ganglionic) subtype (27). The result was $\eta_{\mathrm{DMPP}}=52 \%$ (Table 1$)$.

Overall, the mean \pm s.d efficiency calculated from CRCs for the 11 agonists described so far (ACh, Nor, CCh, Ana, TMA, DMP, DMT, Cho, 4OH-BTMA, 4OH-PTMA, DMPP) is $52 \pm 2 \%$. For this entire group of ligands, that covers a huge range in potency and efficacy, the binding energy ratio $\log \mathrm{K}_{\mathrm{dC}} / \log \mathrm{K}_{\mathrm{do}}$ is 0.48 . Hence, for all of these agonists binding energy increases by a factor of 2.1 (the inverse of this ratio) when the liganded sites switch from low- to high-affinity at the beginning of the global, channelopening transition.

Fig. 4A middle shows CRCs for 3 agonists that have a bridge in their head-group. The efficiency values for epibatidine, epiboxidine and cytisine calculated from $\mathrm{P}_{\mathrm{O}}$ max and $\mathrm{EC}_{50}$ were $\eta_{\mathrm{ebt}}=41 \%, \eta_{\mathrm{ebx}}=46 \%$ and $\eta_{\mathrm{cyt}}=40 \%$. The first two values are similar those estimated previously by kinetic modeling at the human $\alpha 1-\delta$ binding site (10).

Fig. 4A right shows CRCs for 3 agonists that have extraordinarily low efficacies and affinities. To study these, we added background mutations that did nothing more than increase $\mathrm{E}_{\mathrm{O}}$ and, hence, increase $\mathrm{P}_{\mathrm{O}}^{\max }$ and left-shift $\mathrm{EC}_{50}$ (Eqs. 2-4). After correcting for the effects of the background mutations, from the CRC parameters we estimate that in wt AChRs $\eta_{\text {TEA }}=40 \%, \eta_{\text {TMP }}=41 \%$ and $\eta_{\text {var }}=35 \%$.

For the group of 6 ligands shown in Fig. 4A middle and right (Ebt, Ebx, Cyt, Var, TEA, TMP) the average efficiency was $41 \pm 4 \%$ (Fig. 4B). For all these ligands, the binding energy ratio $\left(\log \mathrm{K}_{\mathrm{dc}} / \log \mathrm{K}_{\mathrm{do}}\right)$ is $\sim 0.60$, indicating that binding energy increases by a factor of $\sim 1.7$ when the sites switch from $\mathrm{C}$ to $\mathrm{O}$. 
Fig. 5A shows a histogram of efficiency values for 17 agonists estimated from single-channel CRCs plus 3 agonists estimated from single-channel kinetic modeling (Atx, Aza, nicotine; Fig. 4C) (10, 28). A goodness of fit test indicates that a bimodal (sum of two Gaussians) frequency distribution is a better fit than a single Gaussian $(\mathrm{F}(3,16)=$ $3.37, \mathrm{P}=0.044)$. The two populations have efficiencies of $51 \pm 2 \%$ and $40 \pm 1 \%$ (mean \pm s.d), which is comparable to the mean efficiencies discussed above.

We also estimated the volumes of the head-group of the agonists (Fig. S5 and Table 1) and plotted these versus efficiency (Fig. 5B). A 2D cluster analysis again shows 2 populations with efficiencies of $\eta_{1}=52 \%(n=12)$ and $\eta_{2}=41 \%(n=8)$ with corresponding volumes of $v_{1}=70.4 \pm 8.8$ and $v_{2}=102.2 \pm 17.8 \AA 3$ (centroid+s.d). There is an inverse relationship between agonist efficiency and head-group volume.

\section{CRCs from whole-cell currents}

Single-channel CRCs may offer an accurate method for estimating $\mathrm{K}_{\mathrm{dC}}$ and $\mathrm{E}_{2}$, but CRCs constructed from whole-cell responses are more common. In order to ascertain the extent to which $\eta$ estimated from whole-cell CRCs might be influenced by slow perfusion (that allows desensitization to reduce some peak amplitudes) and heterogeneous receptor properties, we measured whole-cell current amplitude as a function of concentration using 4 agonists, 3 from the high-efficiency group (ACh, CCh and TMA) and 1 from the low-efficiency group (Ebt).

In whole-cell CRCs with maximums normalized to the response to $300 \mu \mathrm{M} A C h$ response (Fig. 6A), $\mathrm{EC}_{50}$ values were left-shifted compared to those in single-channel CRCs by an amount that increased with agonist efficacy (Table 2, left). For example, the 
left-shift was more substantial for ACh $(12.2 \mu \mathrm{M}$ versus $43 \mu \mathrm{M})$ than for TMA (o.84 mM versus $1.2 \mathrm{mM}$ ). An independent whole-cell CRC measurement, also made using an automated patch clamp and adult-type AChRs, was $22 \mu \mathrm{M}$ for $\mathrm{EC}_{50}$ for $\mathrm{ACh}$ (29). We attribute this left-shift to desensitization (see Materials and Methods). Despite this error, for all 4 agonists the efficiency values estimated from whole-cell CRCs were only slightly smaller than those estimated from single-channel measurements.

Because the number of receptors contributing to responses varies from cell to cell and with time, whole-cell CRCs are often normalized so that to the maximum response for each agonist is 1 . We did this for the 4 whole-cell CRCs to estimate new values for $\mathrm{EC}_{50}$ (Fig. 6B and Table 2, right). It was not possible to estimate efficiency from these plots because information regarding efficacy was removed, but below we show that with knowledge of $\eta$ and $I^{\min }$, Imax can be recovered from $\mathrm{EC}_{50}$ of a CRC that has been normalized to 1 .

\section{Binding site mutations}

$\mathrm{K}_{\mathrm{dC}}$ and $\mathrm{K}_{\mathrm{do}}$ have been measured by kinetic modeling of single-channel currents from mouse, adult-type AChRs having a mutation at one of the 5 aromatic residues at each of the 2 binding sites (30). We calculated from these values $\eta_{\text {ACh }}$ for 21 different mutants (Table S1). Fig. $7 \mathrm{~A}$ shows that the distribution is Gaussian with $\eta_{\mathrm{ACh}}=51 \pm 4 \%$ (mean \pm s.d.), which is the same as in wt AChRs. The exceptions were $\alpha$ Y190A (in loop C) that decreased $\eta_{\text {Ach }}$ to $35 \%$, and mutations of $\alpha \mathrm{W} 149$ (in loop B) that increased $\eta_{\mathrm{ACh}}$ by up to $60 \%$ in $\alpha \mathrm{W} 149 \mathrm{~A}$. Removal of the $\alpha \mathrm{Y} 190$ side chain results in a $\sim 30 \%$ decrease 
in efficiency, whereas removal of the $\alpha \mathrm{W} 149$ side chain results in a $\sim 20 \%$ increase in efficiency.

Mutations of a residue on the complementary side of the binding site, $\varepsilon$ P121, had little effect on ACh efficiency except, perhaps, for the slow-channel myaesthenic syndrome mutation $\varepsilon$ P121L (31).

Binding and gating equilibrium constants have also been reported for AChRs having a mutation of $\alpha \mathrm{G} 153$ (28). This amino acid is in loop B and close to $\alpha \mathrm{W} 149$ but does not appear to contact the agonist directly. However, $\alpha \mathrm{G} 153$ is interesting because so far it is the only binding site amino acid we know of where mutations decrease $\mathrm{K}_{\mathrm{dC}}$ (increase binding energy) and increase significantly $\mathrm{E}_{\mathrm{o}}$. We calculated efficiencies from $\mathrm{K}_{\mathrm{dC}}, \mathrm{E}_{2}$ and $\mathrm{E}_{\mathrm{o}}$ values for 16 different $\alpha \mathrm{G} 153$ mutant/agonist combinations using agonists from the high-efficiency population (Table S2).

The distribution of these efficiencies is shown in Fig. $7 \mathrm{~B}$. With a $\alpha \mathrm{G} 153$ mutation, $\eta 42 \pm 3 \%$, which is $\sim 20 \%$ smaller than the wt. This is the same efficiency as the low-efficiency agonist population in wt AChRs. $\alpha \mathrm{G} 153$ mutations that increase affinity also decrease efficiency. The extent of the reduction in $\eta$ was similar for all agonists and side chain substitutions, with the exception of $\alpha \mathrm{G} 153 \mathrm{~K}+$ nicotine. In summary, it appears that a glycine at position $\alpha 153$ allows high efficiency for smallvolume agonists that otherwise take on the low efficiency characteristic of large-volume agonists.

\section{Putting efficiency to use}


In this section we show how knowledge of $\eta$ can simplify and extend CRC analysis. The same efficiency for a group of agonists means that for all, the $\log \mathrm{K}_{\mathrm{dC}} / \log \mathrm{K}_{\mathrm{do}}$ ratio is the same. Hence, the two equilibrium dissociation constants are related by an exponent,

$$
\mathrm{K}_{\mathrm{dC}}=\mathrm{K}_{\mathrm{dO}}{ }^{{ }^{-}{ }^{\eta}} \text { Eq. } 6
$$

With knowledge of $\eta$, only one of the equilibrium dissociation constants needs to be measured. The value of the exponent in Eq. 6 in wt AChRs is $\sim 0.5$ for the high-efficiency group of agonists and $\sim 0.6$ for the low-efficiency group. Accordingly, Eq. 2 becomes

$$
\left(\mathrm{E}_{2} / \mathrm{E}_{\mathrm{o}}\right)=\mathrm{K}_{\mathrm{dC}} \mathrm{p} \quad \mathrm{Eq} \cdot 7
$$

where

$$
\mathrm{p}=2 \eta /(\eta-1)
$$

The 2 reflects the number of equivalent binding sites. For the higher efficiency group $(\eta=0.5), p=-2.00$ and for the lower efficiency group $(\eta=0.4), p=-1.33$

Taking the log of Eq. 7 and rearranging,

$$
\log \mathrm{E}_{2}=\text { plog } \mathrm{K}_{\mathrm{dC}}+\log \mathrm{E}_{\mathrm{o}} \quad \text { Eq. } 8
$$

This equation describes an 'efficiency' plot, with the x-axis being proportional to agonist binding energy $\left(\log \mathrm{K}_{\mathrm{dC}}\right)$ and the $\mathrm{y}$-axis being proportional to gating energy $\left(\log \mathrm{E}_{2}\right)$. For a group of agonists having the same efficiency, a log-log plot of gating versus binding equilibrium constants is a straight line with a slope (p) that depends on efficiency and a y-intercept that gives the unliganded gating equilibrium constant (Eq. 8). Previously, these constants determined from kinetic modeling were used to estimate average $\eta$ values for $4 \mathrm{ACh}$ - and Ebt-class agonists at individual AChR binding sites (10). In addition, values of these constants obtained from the literature were fitted by Eq. 8 to 
estimate $E_{o}$ and average $\eta$ values for agonists of other receptors, with off-line points reflecting agonists having other efficiencies.

The clustering of AChR efficiency values into 2 populations that correlate with agonist size (Fig. 5) suggests that it may someday be possible to predict approximately an agonist's efficiency a priori from its structure and that of the binding cavity. For example, it is reasonable to guess that in adult-type muscle AChRs other choline or nicotine derivatives will have $\eta \sim 50 \%$, and that congeners of Ebt and TEA will have $\eta \sim 40 \%$. More experiments are needed to test the hypothesis that head-group volume and binding site structure in combination can be used to estimate $\eta$. We again note that $\mathrm{E}_{\mathrm{o}}\left(\mathrm{I}^{\mathrm{min}}\right)$ is agonist-independent and needs to be measured only once, so perhaps in the future this important constant will be known for many different receptors.

Given prior knowledge of agonist $\eta$ and receptor $\mathrm{I}^{\mathrm{min}}$, the $\mathrm{CRC}$ parameters $\mathrm{EC}_{50}$ and Imax (the response at a single, high agonist concentration) can be estimated from each other, as follows.

First, we calculate $\mathrm{EC}_{50}$ from $\mathrm{I}^{\mathrm{max}}$ (whole-cell $\mathrm{CRCs}$ normalized to an $\mathrm{ACh}$ response; Table 2, left). The procedure is to solve $E_{2}$ from $I^{\max }$ (Eq. 4), then $\mathrm{K}_{\mathrm{dC}}$ (Eq. 7; $\eta$ equal to the value shown in Table 2) and then $\mathrm{EC}_{50}$ (Eq. 3). Fig. $8 \mathrm{~B}$ (left) shows that calculated and experimental $\mathrm{EC}_{5 \mathrm{o}}$ values are correlated (Pearson's correlation, $\mathrm{r}^{2}=0.78$, $\mathrm{P}<0.0001$ ). Fig. 8C (left) shows that there is a good match between experimental current amplitudes normalized to an ACh response (Fig. 6A) and those calculated from $\eta$ according to Eq. 1 using the new $\mathrm{EC}_{50}$ estimates. $\mathrm{E}_{2}$ has been measured for many AChR agonists (26). Using the above procedure, we estimated corresponding $\mathrm{EC}_{50}$ values assuming $\eta=51 \%$ and $\mathrm{E}_{0}=7.4 \times 10^{-7}$ (Table $\mathrm{S}_{3}$ ). CRCs for these agonists have not 
been measured, but doing so would test further the ability to use $\eta$ and $E_{o}$ to calculate $\mathrm{EC}_{50}$ from $\mathrm{P}_{\mathrm{O}}$ max.

Second, we calculate $\mathrm{I}^{\max }$ from $\mathrm{EC}_{50}$ values (whole-cell CRCs normalized to 1; Table 2, right). Solving Eqs. 7 and 3 for $\mathrm{K}_{\mathrm{dC}}$ and setting them equal yields,

$$
\frac{E C_{50}\left(E_{2}+1\right)}{\sqrt{\left(\mathrm{E}_{2}+2\right)}}=\left(\frac{E_{2}}{E_{0}}\right)^{(1 / \mathrm{p})} . \quad \text { Eq. } 9
$$

$\mathrm{E}_{2}$ and $\mathrm{E}_{\mathrm{o}}$ can be calculated from $\mathrm{I}^{\max }$ and $\mathrm{I}^{\min }$ (Eq. 4). We solved Eq. 9 for $\mathrm{I}^{\max }$ using known values for $\eta$ and $\mathrm{I}^{\mathrm{min}}$ and $\mathrm{EC}_{50}$ from normalized CRCs. Fig. $8 \mathrm{~B}$ (right) is a plot of calculated versus experimental $\mathrm{P}_{\mathrm{O}}{ }^{\max }$ values from single-channel CRCs using an approximate value for $\eta$, either $50 \%$ (ACh, CCh, TMA) or $40 \%$ (Ebt). Again, there is rough agreement (Pearson's correlation, $\left.\mathrm{r}^{2}=0.74, \mathrm{P}<0.0001\right)$. Next, these calculated $\mathrm{I}^{\mathrm{max}}$ values were used to generate CRCs (Eq. 1) that were compared to experimental ones that were not normalized to 1 (Fig. $8 \mathrm{C}$, right). The match is good for $\mathrm{ACh}, \mathrm{CCh}$ and Ebt, but not for TMA. Increasing $\eta_{\text {TMA }}$ from 0.50 to 0.55 makes the calculated and experimental curves match more closely. The $\mathrm{I}^{\max }$ value calculated from $\mathrm{EC}_{50}$ by using Eq. 9 is sensitive to the value of $\eta$ (Fig. S6). Nonetheless, knowledge of agonist efficiency allows efficacy information to be recovered approximately from a CRC that has been normalized to a maximum response of 1.

In addition, knowledge of $\eta$ allows the estimation of $E_{o}$ from a single CRC. $E_{o}$ is of critical importance because it sets the baseline level from which agonists increase $\mathrm{P}_{\mathrm{O}}$, but it is often small and difficult to measure directly $(8,32,33)$. However, a fold-change in $E_{o}$ caused by a mutation or a modulator will produce the same fold-change in $E_{2}$ (Eq. 2) and, hence, a change in both $\mathrm{EC}_{50}$ and $\mathrm{P}_{0} \max (E q s .3$ and 4). 
The procedure we used to estimate $\mathrm{E}_{\mathrm{o}}\left(\mathrm{I}^{\mathrm{min}}\right)$ from a CRC of a wt receptor is first to solve for $\mathrm{E}_{2}$ and $\mathrm{K}_{\mathrm{dC}}$ from $\mathrm{P}_{\mathrm{O}} \max$ and $\mathrm{EC}_{50}$ as described above, then solve for $\mathrm{E}_{\mathrm{o}}$ by using Eq. 8. Fig. S7 shows $E_{0}$ values so-calculated from single-channel CRC parameters. The mean result is reasonably close to the experimentally-determined value (17).

Finally, it is possible to gain an approximate estimate of $\eta$ from CRC parameters in a single step. Taking the log of Eq. 9 and rearranging,

$$
\begin{gathered}
p=\frac{\log E_{2}-\log E_{0}}{\log E C_{50}-A} \\
\mathrm{~A}=0.5 \log \left(\mathrm{E}_{2}+2\right)-\log \left(\mathrm{E}_{2}+1\right) \quad \text { Eq. } 10 \\
\eta=\mathrm{p} /(\mathrm{p}-2) .
\end{gathered}
$$

$\mathrm{E}_{2}=\mathrm{I}^{\max } /\left(1-\mathrm{I}^{\max }\right)$ and $\mathrm{E}_{0}=\mathrm{I}^{\min }$. For many $\mathrm{AChR}$ agonists $\mathrm{E}_{2}<25$ and $\mathrm{EC}_{50}<1 \mathrm{O}^{-3} \mathrm{M}$, so A will usually be much less than $\log \left(\mathrm{EC}_{50}\right)$. Hence, a reasonable approximation for agonist efficiency can be obtained simply by using Eq. 10 with A equal to zero. Fig. 8A shows that $\eta$-values calculated using this shortcut indeed approximate the more-exact values calculated stepwise using Eq. 2-5. 


\section{Discussion}

The notion of agonist efficiency arose from an experimental observation - in neuromuscular AChRs, the binding energy ratio $\log \mathrm{K}_{\mathrm{dC}} / \log \mathrm{K}_{\mathrm{dO}}$ is the same for many different nicotinic agonists (23). Later, this ratio was associated with the efficiency at which agonist binding energy is converted into receptor gating energy (10). Here, we show that agonist efficiency can be estimated from the asymptotes and midpoint of a CRC. Below, we discuss the nature and distribution of efficiency values obtained from single-channel and whole-cell CRCs, some structural implications of efficiency, and applications of efficiency to CRC analysis.

\section{Efficiency}

Agonist efficiencies are the same whether obtained from single-channel or wholecell currents, and from a CRC or by detailed kinetic modeling. They are the same in wild-type AChRs that have 2 binding sites or in crippled AChRs that have just 1 operational site. Efficiency values are the same in mouse and human AChRs and with many mutations at the binding sites (exceptions discussed below) or in distant regions that do not affect binding. In AChRs, efficiency is a robust agonist attribute. At adult neuromuscular synapses, half of the available neurotransmitter binding energy is converted into kinetic energy of the channel-opening conformational change.

In AChRs there are 2 populations of $\eta$-values, at $51 \pm 2 \%$ and $40 \pm 4 \%$ (Fig. $5 \mathrm{~A}$ ). Despite the small standard deviations, we suspect that the variance within each group arises from actual, ligand-specific differences rather than from measurement errors, for the following reasons. i) Efficiency is a ratio of logarithms and therefore is not sensitive to errors in the measured values of $\mathrm{EC}_{50}$ and $\mathrm{P}_{\mathrm{O}}{ }^{\max }$. For example, changing $\mathrm{EC}_{50}$ or 
$\mathrm{P}_{\mathrm{O}} \max ($ Table 1$)$ by $\pm 10 \%$ changes the calculated $\eta$ value by $<1 \%$. ii) The order of $\eta$-values within the high efficiency group is the same in single-channel and whole-cell experiments (TMA $>\mathrm{CCh}>\mathrm{ACh}$ ). iii) A small difference in efficiency leads to a large difference in efficacy calculated from $\mathrm{EC}_{50}$ (Fig. S6). The single-channel $\eta$-value for TMA predicts the experimental, whole-cell CRC more-accurately than does the group value (Fig. 8C, right). We hypothesize that the efficiency difference between, for example, ACh and TMA is meaningful (Fig. 3B).

The observation that mutations of $\alpha \mathrm{G} 153$ shift $\eta$ for 4 agonists from the high- to the low-efficiency population supports the existence of two discrete $\eta$ populations. Although the distribution of agonist efficiency appears to be modal rather than continuous, the high accuracy of experimental $\eta$ estimates must be considered. More experiments might reveal if other $\eta$ populations exist or if small differences between agonists or mutations are meaningful. For example, the observations that $\eta$ is modestly lower with $\varepsilon$ P121 substitutions (Table S1), higher with most non-aromatic substitutions of $\alpha$ Y198 (Table S1) and usually lowest with a K substitution at $\alpha \mathrm{G} 143$ (Table S2) might prove to be meaningful. Likewise, experiments might show that the $35 \%$ efficiency values for varenicline and $\mathrm{ACh}+\alpha \mathrm{Y} 190 \mathrm{~A}$ indicate the existence of a third population.

\section{$\underline{\text { Structural implications }}$}

That a group of agonists have the same efficiency means that all members have the same binding energy ratio, $\log \mathrm{K}_{\mathrm{dC}} / \log \mathrm{K}_{\mathrm{dO}}$ (Eq. 5). Below, we discuss implications of this result with regards to i) rearrangements at the binding site, ii) agonist volume, iii) the bimodal efficiency distribution and iv) binding-site mutations. 
The energy of low-affinity binding is proportional to $\log \mathrm{K}_{\mathrm{dC}}$ and is determined mainly not by diffusion but rather by a local rearrangement at the binding site called 'catch'. The energy of the switch from low- to high-affinity is proportional to $\left(\log \mathrm{K}_{\mathrm{do}}-\right.$ $\log \mathrm{K}_{\mathrm{dc}}$ ), occurs at the beginning of the global, channel-opening isomerization and is called 'hold' (30,34). As discussed elsewhere (34), 'hold' is related to, and possibly the same as, an intermediate (pre-opening) gating state called 'flip' that has been detected directly $(35,36)$. 'Flip' refers to a brief shut state that is high affinity, and 'hold' refers to the rearrangement of the binding site that generates such a state (37). Regardless, a group efficiency implies that for all members, the energy change in hold is $1 /(1-\eta)$ times that of catch. This factor is $\sim 2$ for high- and $\sim 1.7$ for low-efficiency agonists.

This linear relationship between catch and hold energy changes suggests that the associated structural changes, too, are related. Accordingly, the observation that many agonists have the same efficiency suggests that the binding-site rearrangements in catch and in hold can be considered as two stages of a single conformational sweep. Although 'binding' and 'gating' have long been considered to be distinct processes (38), a group efficiency implies that they are components of a multipart structural-change cascade. In AChRs, this cascade begins with a 'touch' by the agonist that takes place after the ligand has diffused to its target but before binding site rearrangements that form the lowaffinity complex, and ends when ions begin to cross the membrane. The 'catch-andhold' sweep of the binding sites is the first part of this cascade, with $\eta$ quantifying the strength of the connection between the binding (catch) and gating (hold) components.

It remains to be determined whether or not a shared binding energy ratio for a group of related agonists is a general feature of receptor activation. It appears that in some receptors other than neuromuscular AChRs there is a linear relationship between 
$\log$ gating and $\log$ binding equilibrium constants for related ligands, and that association to $\mathrm{C}$ is slower than diffusion. These results raise the possibility that a shared $\log \mathrm{K}_{\mathrm{dc}} / \log \mathrm{K}_{\mathrm{do}}$ ratio and a correlation between structural changes in low- and highaffinity complex formation are not exclusive to AChRs (10).

Members of both efficiency populations can have a quaternary amine (TMA, TEA) or a secondary amine (DMPP, Ebt). Hence, it does not appear that the bimodal distribution in efficiency reflects this aspect of the agonist's head group. The inverse correlation between agonist head-group volume and efficiency is more relevant (Fig. ${ }_{5}$ B). Simulations of AChR structures suggest that the agonist binding cavity is smaller in $\mathrm{O}$ compared to in $\mathrm{C}$ and, hence, that binding site contraction is a structural correlate of 'hold' (25). In addition, kinetic analyses of AChR gating indicate that in the channelopening isomerization, 'hold' is followed by a rearrangement of the extracellular domain $(4,34,39,40)$.

These results lead to hypothesize that large-volume, low-efficiency agonists encounter steric hindrance when the binding cavity contracts in 'hold', to limit the shrinkage and, hence, the mechanical force applied to the next element in the gating sequence, the extracellular domain. We imagine that small, high-efficiency ligands fit comfortably into both $\mathrm{C}$ and $\mathrm{O}$ pockets but that large, low-efficiency agonists do not fit easily into the smaller O cavity and so support a smaller contraction. According to this hypothesis, large ligands transfer less energy to the next step in the conformational cascade and thus have low efficiencies.

In support of this idea, the smallest agonists we tested, DMP, DMT and TMA, have the largest efficiencies (Fig. 3B). Further, simulations show that compared to ACh, the binding cavity is smaller with TMA and the extent of cavity contraction is smaller 
with the low-efficiency agonist Ebx (25). However, the relationship between agonist volume and efficiency is not simple because Ebt and TEA have similar efficiencies despite a substantial difference in volume (Table 1).

There are 2 efficiency populations (Fig. 5A). One possible explanation is that each efficiency group reflects a different 'hold' binding site conformation. In this view, the high-affinity cavity can adopt only a limited number (so far, 2) of 'preset' structures and is not malleable or able to adapt its shape to each agonist. Perhaps small versus large agonists allow the pocket to adopt alternative contracted shapes, with all agonists larger than some threshold forcing the less-efficient shape. Another hypothesis for the bimodal distribution of $\eta$ is that there are two discrete energy transfer pathways that supply energy for activating the extracellular domain. Both paths are activated with smaller agonists but one (or both) is compromised when the pocket is 'stretched' by a large ligand. Both of these hypotheses are speculations that can be tested experimentally.

Aromatic side chains at the binding site govern agonist affinity. While most mutations of these have little or no effect on $\eta$, another clue regarding the structural basis of efficiency is that the efficiency of ACh is reduced by $30 \%$ by the mutation $\alpha$ Y190A (in loop C) and increased by $20 \%$ by the mutation $\alpha W 149 \mathrm{~A}$ (in loop B). $\alpha \mathrm{Y}_{190}$ appears to be the most-important aromatic side chain with regards to the propagation of structural changes from the binding site in channel opening $(22,41)$. That the mutations $\alpha Y 190 F$ and $\alpha Y 190 W$ have little effect on ACh efficiency suggests that the key interaction here is with the aromatic ring rather than with the $\mathrm{OH}$ group.

All 4 mutations of $\alpha \mathrm{G} 153$ (in loop B) reduced the efficiency of all 4 tested agonists. Again, the drop appeared to be modal, reducing the average efficiency from 
$51 \%$ to $42 \%$. At this juncture we do not have a hypothesis for the structural basis for this

decrease in efficiency. Perhaps molecular dynamics simulations can test if flexibility of the loop B backbone promotes high efficiency. It will be worthwhile to ascertain experimentally the extent to which the $\alpha \mathrm{W} 149 \mathrm{~A}$ and $\alpha \mathrm{G} 153$ mutations are correlated.

Efficiency estimates for the two populations are the same whether measured in whole receptors (that have $\alpha-\delta$ and $\alpha-\varepsilon$ binding sites) or in receptors having only one functional site (10). This indicates that the energy changes that contribute to efficiency are determined mainly by local ligand-protein interactions at each binding site, with little or no energy transfer between sites. The efficiency of Ebx is somewhat higher in whole receptors compared to at $\alpha-\delta$ alone so it is possible that the efficiency of this agonist is modestly greater at one site $(\alpha-\varepsilon)$ compared to the other. Agonist affinity is greatest at the fetal $(\alpha 1-\gamma)$ neurotransmitter binding sites (56\% for ACh) and it is possible that the some of the small, agonist-dependent differences in $\eta$ between adult sites are meaningful.

\section{Applications}

Because $\eta$ values are modal, efficiency can be used to classify agonists. Someday, efficiency may stand alongside affinity and efficacy as a core agonist attribute. An approximate value for agonist efficiency can be calculated from CRC parameters by using Eq. 10, with $\mathrm{A}=\mathrm{O}$ (Fig. 8A). To make the calculation even easier, Eq. 10 can be rearranged to express $\eta$ directly in terms of CRC parameters,

$$
\frac{1}{\eta} \approx\left(1-\frac{n \log \left(E C_{50}\right)}{\log \left(\frac{I^{\max }}{1-I^{\max }}\right)-\log \left(I^{\min }\right)}\right), \quad \text { Eq. } 11
$$


where $\mathrm{n}$ is the number of agonist binding sites and is proportional to $\mathrm{n}_{H}(42)$. Eq. 11 offers an easy way to estimate approximately an agonist's efficiency from a CRC. If Imin is not known, it may be possible to compare efficiencies of different agonists by using a common value, for instance $10^{-6}$.

Knowing $\eta$ is useful because it allows $\mathrm{EC}_{50}$ and $\mathrm{I}^{\mathrm{max}}$ to be estimated from each other. With knowledge of $\eta, \mathrm{EC}_{50}$ and an entire $\mathrm{CRC}$ can be calculated knowing only the responses at the low- and high-concentration asymptotes (Fig. 8C). Given $\eta$ and Imin, the response at just one agonist concentration, that which produces $I^{\text {max }}$, needs to be measured in order to estimate $\mathrm{EC}_{50}$. Having this ability could facilitate drug screening.

It is common practice in CRCs to normalize Imax to 1 and lose information regarding agonist efficacy. We have shown that given prior knowledge of $\eta$ and ${ }^{\text {min }}$, and an experimental estimate of $\mathrm{EC}_{50}$, Eq. 9 can be solved numerically for $\mathrm{E}_{2}$ and, hence, Imax. The ability to compute an absolute CRC from a normalized one could be useful once the values of the agonist's efficiency and the receptor's constitutive activity are established. The main caveat is that the calculated efficacy is very sensitive to the value of $\eta$.

\section{Author contributions:}

Dinesh C. Indurthi: designed and performed research; analyzed data.

Anthony Auerbach: conceptualized and designed research; analyzed data and wrote the manuscript. 
Acknowledgements: We thank Mary Teeling, Marlene Shero and Janet Jordan for technical assistance and Pablo M. Paez for allowing access to his IonFlux. Supported by NS-064969 and GM-121463

Competing interests: The authors declare no competing financial or non-financial interests. 


\section{Figure legends}

Figure 1. Cyclic activation of AChRs (Scheme 1). Receptors switch between $\mathrm{C}($ losed-channel) and O(pen-channel) conformations spontaneously (influenced only by temperature) with or without agonists (A). Equilibrium constants: $E_{n}$, gating with $n$ bound agonists; $\mathrm{K}_{\mathrm{dC}}$ and $\mathrm{K}_{\mathrm{do}}$, dissociation constants to $\mathrm{C}$ (low affinity) and to $\mathrm{O}$ (high affinity). The adult-type, endplate AChR binding sites are approximately equivalent and independent with regards to the agonists used in this study. From experiments and microscopic reversibility, $\mathrm{E}_{2} / \mathrm{E}_{0}=\left(\mathrm{K}_{\mathrm{dc}} / \mathrm{K}_{\mathrm{dO}}\right)^{2}$. Agonists increase activity above the baseline level because they bind more-strongly to the $\mathrm{C}-\mathrm{O}$ transition state, with the extra binding energy serving to increase the channel-opening rate constant (red arrows). Thick arrows and bold letters mark the physiological activation-deactivation pathway.

Figure 2. Single-channel current CRCs. A. Low-resolution view of cell-attached, single-channel currents activated by epibatidine (Ebt; open is down). Clusters of open/shut intervals from one AChR separated by silent periods in which all AChRs in the patch are desensitized. B. Left, high-resolution views of example clusters at different Ebt concentrations. Right, corresponding intra-cluster interval-duration histograms. $\tau_{\mathrm{s}}$ and $\tau_{0}$, predominant shut- and open-interval time constants (in ms). Open-channel probability $\left(\mathrm{P}_{0}\right)$ at each agonist concentration is $\tau_{0} /\left(\tau_{\mathrm{s}}+\tau_{0}\right)$. C. Each CRC was fitted by Eq. 1 to estimate $\mathrm{EC}_{50}$ and $\mathrm{P}_{0}{ }^{\max }$ (symbols, mean \pm s.e.m.). Efficiency $(\eta)$ was calculated by using Eqs. 2-5. It is apparent that ACh is more efficient than Ebt because the same $\mathrm{EC}_{50}$ is associated with a greater $\mathrm{P}_{\mathrm{O}}$ max 
Figure 3. Efficiencies from single-channel CRCs. A. CRCs of 7 agonists in adulttype mouse AChRs (re-plotted from (23)). There is an inverse correlation between $\mathrm{EC}_{50}$ and $\mathrm{P}_{\mathrm{O}} \max \left(\right.$ Table 1). B. Agonist efficiencies calculated from $\mathrm{EC}_{50}$ and $\mathrm{P}_{\mathrm{O}}$ max. All agonists have a similar efficiency (average, 52\%; dashed line). C. Agonist structures (see Materials and Methods for abbreviations). Red, key nitrogen atom in the agonist's head-group.

Figure 4. Efficiencies from more single-channel CRCs. A. Single-channel CRCs of 9 agonists in adult-type mouse AChRs (symbols, mean \pm s.e.m.). In some cases background mutations were used to increase constitutive gating and, hence, increase $\mathrm{P}_{\mathrm{O}}$ max and left-shift $\mathrm{EC}_{50}\left(\varepsilon \mathrm{S} 45 \mathrm{OW}\right.$, left and middle; $\varepsilon \mathrm{L} 269 \mathrm{~F}+\varepsilon \mathrm{E} 181 \mathrm{~W}$, right). $\mathrm{EC}_{5 \mathrm{o}}$ and $\mathrm{P}_{\mathrm{O}}$ max values in Table 1 have been corrected for these backgrounds and pertain to wt AChRs. B. Efficiencies calculated from the CRCs (open bars) or from previously reported measurements of $\mathrm{K}_{\mathrm{dC}}$ and $\mathrm{K}_{\mathrm{do}}$ obtained by kinetic modeling (gray bars; $(5$, 28)). There are 2 populations with average efficiencies of $50 \%$ and $41 \%$ (dashed lines). C. Agonist structures. Red, key nitrogen or phosphorous atom in the agonist's headgroup.

Figure 5. Distribution of agonist efficiency. A. Distribution of efficiencies for 20 agonists, fitted by the sum of two Gaussians. There are 2 populations at $\eta=51 \pm 2 \%$ and $40 \pm 4 \%$ (mean \pm s.d.). B. 2-D scatter plot of efficiency versus head-group volume (v). Cluster analysis (k-means) shows that there are 2 populations with $\eta / v$ centroids at $52 \% / 70.4 \mathrm{~A}^{3}$ (red) and 41\%/102.2 $\mathrm{A}^{3}$ (blue). 
Figure 6. Whole-cell current CRCs. A. Each current response was normalized to that of $300 \mu \mathrm{M}$ ACh $\left(\mathrm{P}_{\mathrm{O}}=0.93\right)$. Imax and $\mathrm{EC}_{50}$ values in Table 2, left. B. CRCs normalized to $\mathrm{Imax}^{\mathrm{m}}=1 . \mathrm{EC}_{50}$ values in Table 2, right. C. Example currents.

Figure 7. Effect of binding-site mutations on agonist efficiency. Mutations were at both adult-type binding sites. A. Mutations of aromatic amino acids and $\varepsilon \mathrm{P} 121$ (agonist, ACh) (Table S1). Arrow marks wt efficiency. The only substitutions to alter efficiency significantly are $\alpha Y 190 \mathrm{~A}$ and $\alpha \mathrm{W} 149 \mathrm{~A}$. Gaussian fit of frequency distribution for 21 mutants (excluding $\alpha Y 190 A$ ) gives $\eta=51 \pm 4 \%$ (mean \pm S.d). B. Mutations of $\alpha \mathrm{G} 153$ activated by 4 high-efficiency agonists (Table S2 and inset) (28). Gaussian fit of frequency distribution for all 16 mutation/agonist combinations gives $\eta=42 \pm 3 \%$.

Figure 8. Using efficiency to calculate CRC parameters. A. Approximate efficiencies calculated in a single step (Eq. 10, with $A=0$ ) match efficiencies calculated in multiple steps (Eqs.2-5). B. If $\square$ and $\mathrm{E}_{0}$ are known, $\mathrm{EC}_{50}$ and $\mathrm{I}^{\max }\left(\mathrm{P}_{0}{ }^{\max }\right)$ can be calculated from each other. Left, calculated versus measured $\mathrm{EC}_{50}$ from single-channel CRCs. $\eta$ for each agonist given in Table 2. Right, calculated versus measured $\mathrm{P}_{\mathrm{O}}{ }^{\text {max }}$ using $\eta=50 \%$ (red) or $40 \%$ (blue). C. Left, CRCs drawn using calculated $\mathrm{EC}_{50}$ and measured Imax (Table 2, left) superimposed on whole-cell current responses (Fig. 6A). Right, CRCs drawn using calculated $\mathrm{I}^{\max }$ and measured $\mathrm{EC}_{50}$ (Table 2, right) using $\eta=50 \%$ for $\mathrm{ACh}$, CCh and TMA and 40\% for Ebt. With TMA, $\eta=55 \%$ improves the match. 


\section{TABLES}

\begin{tabular}{|c|c|c|c|c|c|c|c|c|c|c|c|c|}
\hline \multirow[b]{2}{*}{ s.no } & \multicolumn{5}{|c|}{ Measured Values } & \multicolumn{7}{|c|}{ Calculated values } \\
\hline & Agonist & $\begin{array}{c}\mathrm{EC}_{50} \pm \text { sem } \\
(\mu \mathrm{M})\end{array}$ & $\mathrm{P}_{\mathrm{o}}^{\max } \pm \mathrm{sem}$ & $\mathbf{n}_{\mathrm{H}}$ & $\mathbf{n}$ & $E_{2}$ & $\begin{array}{c}\mathrm{K}_{\mathrm{dc}} \\
(\mu \mathrm{M})\end{array}$ & $\begin{array}{c}K_{\mathrm{do}} \\
(\mathrm{nM})\end{array}$ & $\log K_{d C}$ & $\log K_{\mathrm{do}}$ & $\square$ & $\begin{array}{c}\text { volume } \\
\left(A^{3}\right)\end{array}$ \\
\hline \multirow[t]{3}{*}{1} & $\mathrm{ACh}^{\square}$ & 43 & 0.96 & 1.7 & - & 23.4 & 174 & 24 & -3.76 & -7.62 & 0.50 & 77 \\
\hline & $\mathrm{ACh}^{\Phi}$ & & & & & & 130 & 18 & -3.89 & -7.74 & 0.50 & \\
\hline & $\mathrm{ACh}^{\psi}$ & 22 & 0.96 & & & 24 & 90 & 12 & -4.04 & -7.91 & 0.49 & \\
\hline 2 & Nor $^{ \pm}$ & 72 & 0.92 & 1.0 & - & 12 & 200 & 38 & -3.70 & -7.41 & 0.50 & 69 \\
\hline 3 & $\mathrm{CCh}^{\square}$ & 320 & 0.84 & 1.6 & - & 5.25 & 542 & 159 & -3.27 & -6.80 & 0.52 & 77 \\
\hline 4 & $\mathrm{Ana}^{ \pm}$ & 524 & 0.78 & 1.2 & - & 3.63 & 719 & 253 & -3.14 & -6.60 & 0.52 & 70 \\
\hline 5 & $\mathrm{TMA}^{\square}$ & 1200 & 0.75 & 1.1 & - & 3 & 1480 & 574 & -2.83 & -6.24 & 0.54 & 77 \\
\hline 6 & $\mathrm{DMT}^{\square}$ & 4200 & 0.42 & 0.8 & - & 0.72 & 2730 & 2150 & -2.56 & -5.67 & 0.54 & 58 \\
\hline 7 & $\mathrm{DMP}^{\square}$ & 6700 & 0.26 & 1.1 & - & 0.35 & 3570 & 4040 & -2.45 & -5.39 & 0.54 & 56 \\
\hline 8 & Cho & 4013 & 0.05 & & - & 0.05 & 4100 & 15100 & -2.39 & -4.82 & 0.50 & 77 \\
\hline 9 & $\mathrm{DMPP}^{\$}$ & $246 \pm 81$ & $0.87 \pm 0.09$ & 1.3 & 3 & 6.69 & 480 & 134 & -3.32 & -6.87 & 0.52 & 59 \\
\hline 10 & $4 \mathrm{OH}-\mathrm{B}^{\$}$ & $2171 \pm 77$ & $0.29 \pm 0.04$ & 0.9 & 3 & 0.41 & 1270 & 1350 & -2.92 & -5.87 & 0.50 & 77 \\
\hline 11 & $3 \mathrm{OH}-\mathrm{P}^{\$}$ & $3485 \pm 10$ & $0.15 \pm 0.02$ & 0.6 & 4 & 0.18 & 1660 & 2840 & -2.78 & -5.55 & 0.50 & 77 \\
\hline 12 & $\mathrm{Ebt}^{\$}$ & $32 \pm 2$ & $0.60 \pm 0.6$ & 1.9 & 4 & 1.50 & 28 & 16 & -4.55 & -7.78 & 0.41 & 88 \\
\hline 13 & $\mathrm{Ebx}^{\$}$ & $90 \pm 4$ & $0.74 \pm 0.02$ & 1.6 & 3 & 2.85 & 108 & 46 & -3.96 & -7.33 & 0.46 & 88 \\
\hline 14 & $\mathrm{Cyt}^{\$}$ & $137 \pm 5$ & $0.18 \pm 0.01$ & 1.3 & 4 & 0.22 & 67 & 104 & -4.17 & -6.99 & 0.40 & 114 \\
\hline 15 & $\operatorname{Var}^{*}$ & $135 \pm 12$ & $0.015 \pm 0.002$ & 4.8 & 3 & 0.02 & 57 & 331 & -4.25 & -6.48 & 0.35 & 102 \\
\hline 16 & TEA $^{*}$ & $4200 \pm 130$ & $0.002 \pm 0.0007$ & 1.1 & 3 & 0.002 & 174 & 26800 & -2.76 & -4.57 & 0.40 & 136 \\
\hline 17 & TMP ${ }^{*}$ & $844 \pm 32$ & $0.03 \pm 0.002$ & 2.5 & 3 & 0.031 & 360 & 1473 & -3.44 & -5.83 & 0.41 & 87 \\
\hline 18 & $\operatorname{Atx}^{\square}$ & & & & & & 115 & 247 & -3.94 & -6.61 & 0.40 & 114 \\
\hline 19 & $\mathrm{Aza}^{\square}$ & & & & & & 934 & 6053 & -3.03 & -5.22 & 0.42 & 88 \\
\hline 20 & $\mathrm{Nic}^{ \pm}$ & & & & & 0.87 & 1000 & 920 & -3.00 & -6.04 & 0.50 & 84 \\
\hline
\end{tabular}

Table 1. Efficiencies from single-channel CRCs. $\mathrm{EC}_{50}, \mathrm{P}_{\mathrm{O}}{ }^{\max }$ and $\mathrm{n}_{\mathrm{H}}$ obtained by using Eq. 1. n, number of CRCs; sem, standard error of the mean. $\mathrm{E}_{2}$, diliganded gating equilibrium constant; $\mathrm{K}_{\mathrm{dC}}$, equilibrium dissociation constant to $\mathrm{C}$; $\mathrm{K}_{\mathrm{do}}$, equilibrium dissociation constant to $\mathrm{O}$ (see Fig. 1). The unliganded gating equilibrium constant $\mathrm{E}_{\mathrm{o}}$ was $5.2 \times 10^{-7}$. $\eta$, efficiency calculated using Eq. 5 ; volume is of the agonist's head-group volume (Fig. S5). Previously published values are from ${ }^{\square}(23),{ }^{ \pm}(28),{ }^{\Phi}(5),{ }^{\Psi}(29),{ }^{\square}(10)$. All entries pertain to wt adult AChRs. 


\begin{tabular}{|c|c|c|c|c|c|c|}
\hline \multirow[b]{2}{*}{ Agonist } & \multicolumn{4}{|c|}{$\mathrm{I}^{\max }=$ response to $300 \mu \mathrm{M} \mathrm{ACh}$} & \multirow{2}{*}{$\begin{array}{c}I^{\max }=1 \\
E^{E C_{50} \pm s e m} \\
(\mu \mathrm{M})\end{array}$} & \multirow[b]{2}{*}{$\mathbf{n}$} \\
\hline & $\begin{array}{c}\mathrm{EC}_{50} \pm \text { sem } \\
(\mu \mathrm{M})\end{array}$ & $I^{\max } \pm$ sem & $\mathbf{n}_{\mathrm{H}}$ & $\eta$ & & \\
\hline ACh & $12.2 \pm 0.7$ & 0.96 & 1.5 & 0.47 & $12.2 \pm 0.7$ & 6 \\
\hline $\mathrm{CCh}$ & $72.2 \pm 11$ & $0.91 \pm 0.04$ & 1.2 & 0.50 & $72.4 \pm 6$ & 6 \\
\hline TMA & $843 \pm 110$ & $0.70 \pm 0.04$ & 1.2 & 0.52 & $1328 \pm 160$ & 4 \\
\hline Ebt & $8.42 \pm 1.0$ & $0.72 \pm 0.02$ & 1.5 & 0.39 & $10 \pm 1.2$ & 8 \\
\hline
\end{tabular}

Table 2. Whole cell CRC parameters and efficiency $(\eta)$ estimates. Left, $\mathrm{EC}_{50}$, $I^{\max }$ and $\mathrm{n}_{\mathrm{H}}$ from CRCs normalized by the response to $300 \mu \mathrm{M}$ ACh (Fig. 6A; Imax for ACh determined from single-channel currents; Imin, 5.9x10-7). Right, $\mathrm{EC}_{50}$ from $\mathrm{CRCs}$ internally normalized to $I^{\max }=1$ (Fig. 6B). n, number of trials (up to 20 cells each). 


\section{References:}

1. Cederholm, J. M., P. R. Schofield, and T. M. Lewis. 2009. Gating mechanisms in Cysloop receptors. Eur Biophys J 39(1):37-49.

2. Gharpure, A., C. M. Noviello, and R. E. Hibbs. 2020. Progress in nicotinic receptor structural biology. Neuropharmacology 171:108086.

3. Cetin, H., D. Beeson, A. Vincent, and R. Webster. 2020. The Structure, Function, and Physiology of the Fetal and Adult Acetylcholine Receptor in Muscle. Front Mol Neurosci 13:581097.

4. Grosman, C., M. Zhou, and A. Auerbach. 2000. Mapping the conformational wave of acetylcholine receptor channel gating. Nature 403(6771):773-776.

5. Nayak, T. K., and A. Auerbach. 2017. Cyclic activation of endplate acetylcholine receptors. Proc Natl Acad Sci U S A 114(45):11914-11919.

6. Auerbach, A. 2020. Pathways for nicotinic receptor desensitization. J Gen Physiol 152(10).

7. Rahman, M. M., J. Teng, B. T. Worrell, C. M. Noviello, M. Lee, A. Karlin, M. H. B. Stowell, and R. E. Hibbs. 2020. Structure of the Native Muscle-type Nicotinic Receptor and Inhibition by Snake Venom Toxins. Neuron 106(6):952-962 e955.

8. Purohit, P., and A. Auerbach. 2009. Unliganded gating of acetylcholine receptor channels. Proc Natl Acad Sci U S A 106(1):115-120.

9. Zhou, M., A. G. Engel, and A. Auerbach. 1999. Serum choline activates mutant acetylcholine receptors that cause slow channel congenital myasthenic syndromes. Proc Natl Acad Sci U S A 96(18):10466-10471.

10. Nayak, T. K., R. Vij, I. Bruhova, J. Shandilya, and A. Auerbach. 2019. Efficiency measures the conversion of agonist binding energy into receptor conformational change. J Gen Physiol 151(4):465-477.

11. Sakmann, B., J. Patlak, and E. Neher. 1980. Single acetylcholine-activated channels show burst-kinetics in presence of desensitizing concentrations of agonist. Nature 286(5768):71-73.

12. Nicolai, C., and F. Sachs. 2013. Solving ion channel kinetics with the QuB software. Biophysical Reviews and Letters 8(03n04):191-211.

13. Qin, F. 2004. Restoration of single-channel currents using the segmental k-means method based on hidden Markov modeling. Biophys J 86(3):1488-1501.

14. Qin, F., A. Auerbach, and F. Sachs. 1997. Maximum likelihood estimation of aggregated Markov processes. Proc Biol Sci 264(1380):375-383.

15. Elenes, S., and A. Auerbach. 2002. Desensitization of diliganded mouse muscle nicotinic acetylcholine receptor channels. J Physiol 541(Pt 2):367-383.

16. Jadey, S. V., P. Purohit, I. Bruhova, T. M. Gregg, and A. Auerbach. 2011. Design and control of acetylcholine receptor conformational change. Proc Natl Acad Sci U S A 108(11):4328-4333.

17. Nayak, T. K., P. G. Purohit, and A. Auerbach. 2012. The intrinsic energy of the gating isomerization of a neuromuscular acetylcholine receptor channel. J Gen Physiol 139(5):349-358.

18. Jha, A., P. Purohit, and A. Auerbach. 2009. Energy and structure of the M2 helix in acetylcholine receptor-channel gating. Biophys J 96(10):4075-4084. 
19. Purohit, P., S. Gupta, S. Jadey, and A. Auerbach. 2013. Functional anatomy of an allosteric protein. Nat Commun 4:2984.

20. Vij, R., P. Purohit, and A. Auerbach. 2015. Modal affinities of endplate acetylcholine receptors caused by loop C mutations. J Gen Physiol 146(5):375-386.

21. Pettersen, E. F., T. D. Goddard, C. C. Huang, G. S. Couch, D. M. Greenblatt, E. C. Meng, and T. E. Ferrin. 2004. UCSF Chimera--a visualization system for exploratory research and analysis. J Comput Chem 25(13):1605-1612.

22. Bruhova, I., and A. Auerbach. 2017. Molecular recognition at cholinergic synapses: acetylcholine versus choline. J Physiol 595(4):1253-1261.

23. Jadey, S., and A. Auerbach. 2012. An integrated catch-and-hold mechanism activates nicotinic acetylcholine receptors. J Gen Physiol 140(1):17-28.

24. Purohit, Y., and C. Grosman. 2006. Estimating binding affinities of the nicotinic receptor for low-efficacy ligands using mixtures of agonists and two-dimensional concentration-response relationships. J Gen Physiol 127(6):719-735.

25. Tripathy, S., W. Zheng, and A. Auerbach. 2019. A single molecular distance predicts agonist binding energy in nicotinic receptors. J Gen Physiol 151(4):452-464.

26. Bruhova, I., T. Gregg, and A. Auerbach. 2013. Energy for wild-type acetylcholine receptor channel gating from different choline derivatives. Biophys J 104(3):565574.

27. Ling, H. W. 1959. Actions of dimethylphenylpiperazinium. Br J Pharmacol Chemother 14:505-511.

28. Jadey, S., P. Purohit, and A. Auerbach. 2013. Action of nicotine and analogs on acetylcholine receptors having mutations of transmitter-binding site residue alphaG153. J Gen Physiol 141(1):95-104.

29. Yehia, A., and H. Wei. 2020. Studying Nicotinic Acetylcholine Receptors Using the IonFlux Microfluidic-Based Automated Patch-Clamp System with Continuous Perfusion and Fast Solution Exchange. Curr Protoc Pharmacol 88(1):e73.

30. Purohit, P., I. Bruhova, S. Gupta, and A. Auerbach. 2014. Catch-and-Hold Activation of Muscle Acetylcholine Receptors Having Transmitter Binding Site Mutations. Biophysical Journal 107(1):88-99.

31. Ohno, K., H. L. Wang, M. Milone, N. Bren, J. M. Brengman, S. Nakano, P. Quiram, J. N. Pruitt, S. M. Sine, and A. G. Engel. 1996. Congenital myasthenic syndrome caused by decreased agonist binding affinity due to a mutation in the acetylcholine receptor epsilon subunit. Neuron 17(1):157-170.

32. Jackson, M. B. 1986. Kinetics of unliganded acetylcholine receptor channel gating. Biophys J 49(3):663-672.

33. Jha, A., and A. Auerbach. 2010. Acetylcholine receptor channels activated by a single agonist molecule. Biophys J 98(9):1840-1846.

34. Gupta, S., S. Chakraborty, R. Vij, and A. Auerbach. 2017. A mechanism for acetylcholine receptor gating based on structure, coupling, phi, and flip. J Gen Physiol 149(1):85-103.

35. Lape, R., D. Colquhoun, and L. G. Sivilotti. 2008. On the nature of partial agonism in the nicotinic receptor superfamily. Nature 454(7205):722-727.

36. Mukhtasimova, N., W. Y. Lee, H. L. Wang, and S. M. Sine. 2009. Detection and trapping of intermediate states priming nicotinic receptor channel opening. Nature 459(7245):451-454. 
37. Auerbach, A. 2005. Gating of acetylcholine receptor channels: brownian motion across a broad transition state. Proc Natl Acad Sci U S A 102(5):1408-1412.

38. Colquhoun, D. 1998. Binding, gating, affinity and efficacy: the interpretation of structure-activity relationships for agonists and of the effects of mutating receptors. Br J Pharmacol 125(5):924-947.

39. Purohit, P., A. Mitra, and A. Auerbach. 2007. A stepwise mechanism for acetylcholine receptor channel gating. Nature 446(7138):930-933.

40. Sauguet, L., A. Shahsavar, F. Poitevin, C. Huon, A. Menny, A. Nemecz, A. Haouz, J. P. Changeux, P. J. Corringer, and M. Delarue. 2014. Crystal structures of a pentameric ligand-gated ion channel provide a mechanism for activation. Proc Natl Acad Sci U S A 111(3):966-971.

41. Mukhtasimova, N., C. Free, and S. M. Sine. 2005. Initial coupling of binding to gating mediated by conserved residues in the muscle nicotinic receptor. J Gen Physiol 126(1):23-39.

42. Qin, F. 2010. Hill coefficients of a polymodal Monod-Wyman-Changeux model for ion channel gating. Biophys J 99(3):L29-31. 
$2 / K_{d C}$

$2 A+C$

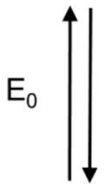

$2 \mathrm{~A}+\mathrm{O}$
$0.5 / K_{d C}$


$A+A O$



$0.5 / \mathrm{K}_{\mathrm{dcO}}$ 
bioRxiv preprint doi: https://doi.org/10.1101/2020.10.13.337410; this version posted February 24,2021 . The copyright holder for this preprint (which was not certified by peer review) is the author/funder, who has granted bioRxiv a license to display the preprint in perpetuity. It is made
available under aCC-BY 4.0 International license.

$1 \mathrm{mM}$ epibatidine (Ebt)



B


$P_{0}=0.05$


$P_{0}=0.02$

$500 \mathrm{~ms}$

$P_{0}=0.43$

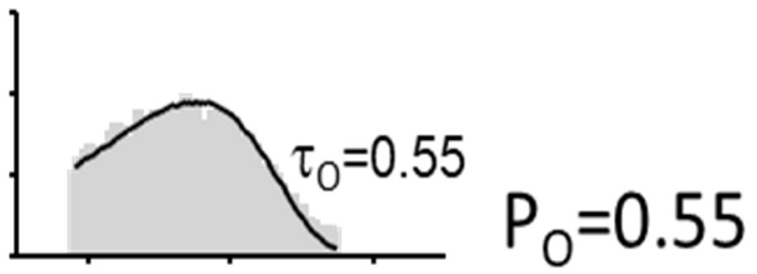

C

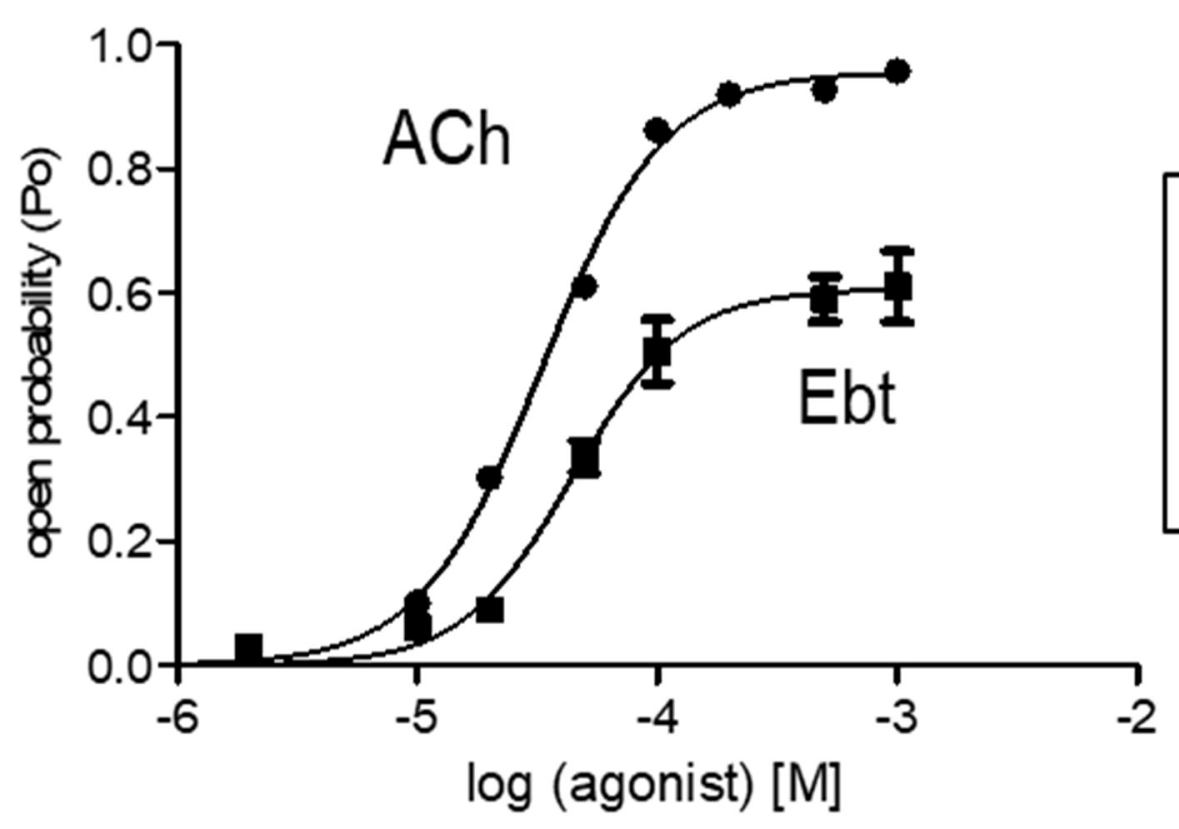


A
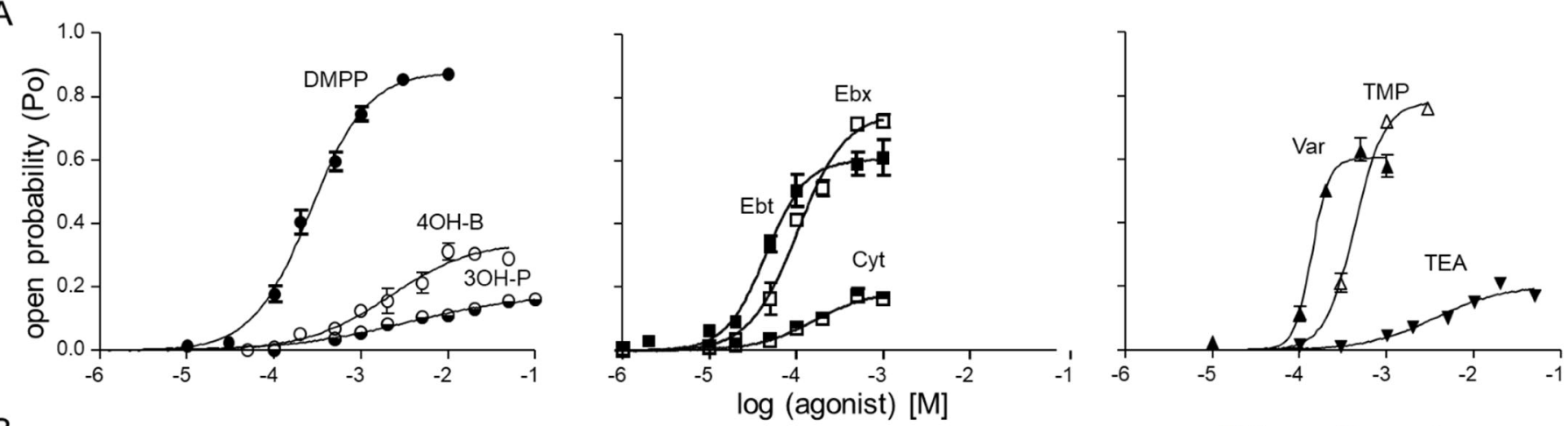

B

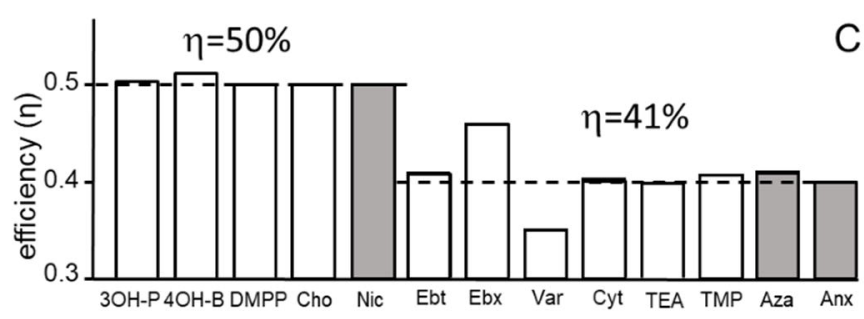

$\mathrm{C}-\mathrm{CHOH}_{3 \mathrm{OH}-\mathrm{P}}^{\mathrm{N}}$

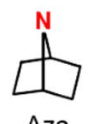

TEA
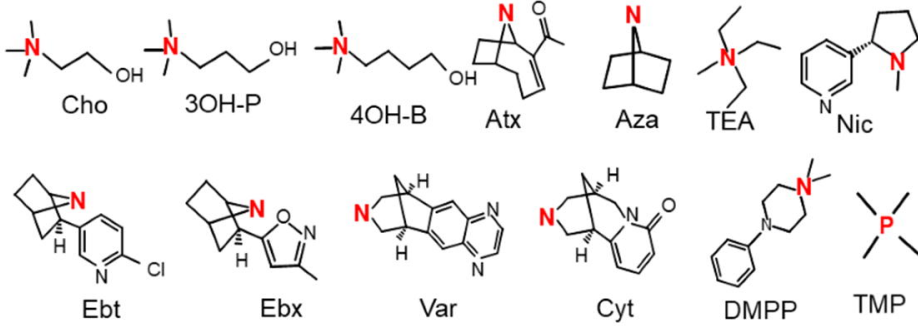

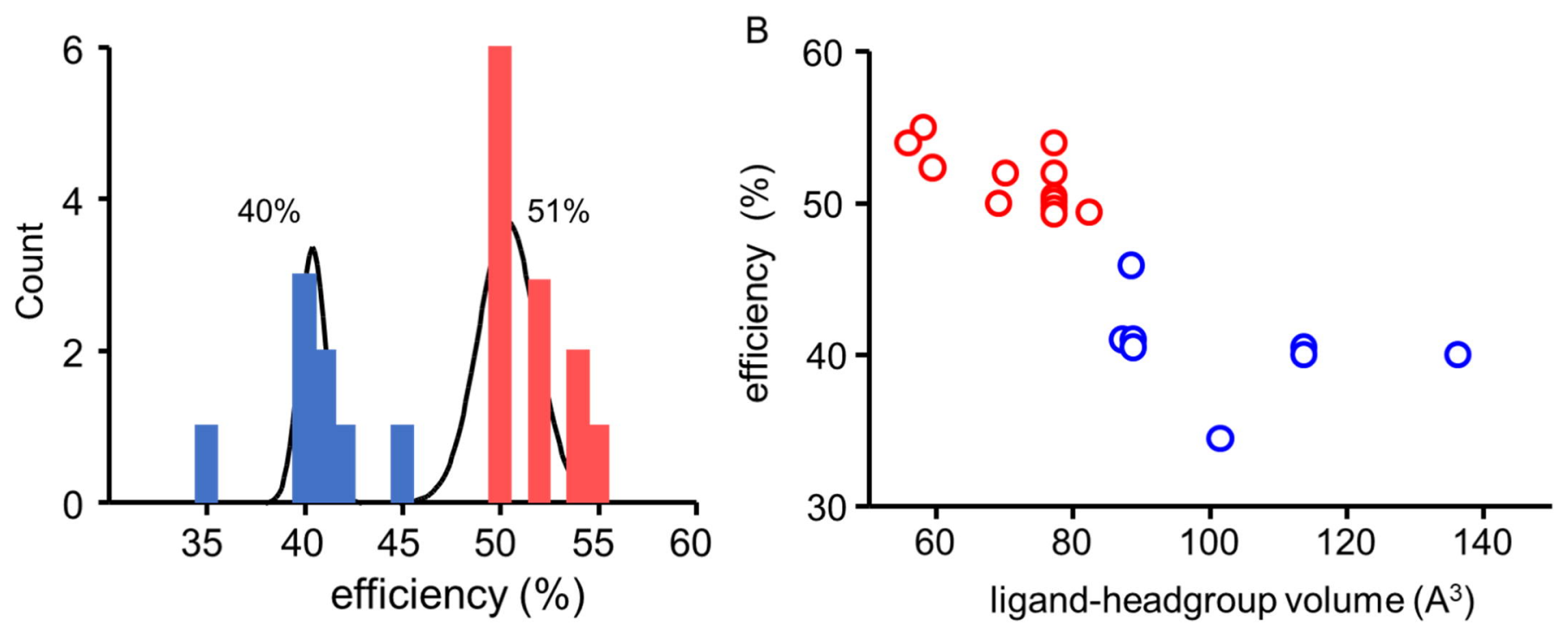
A
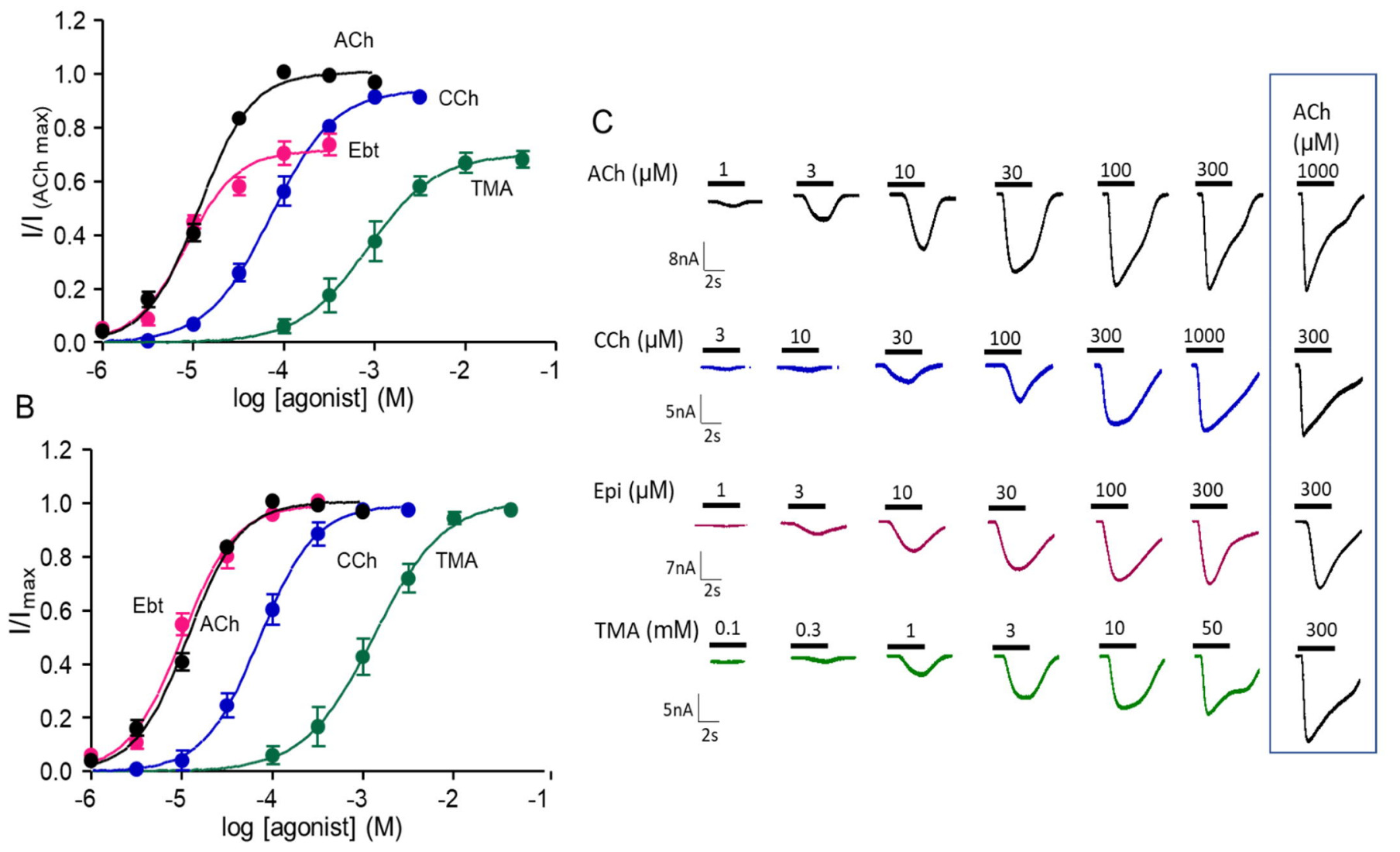

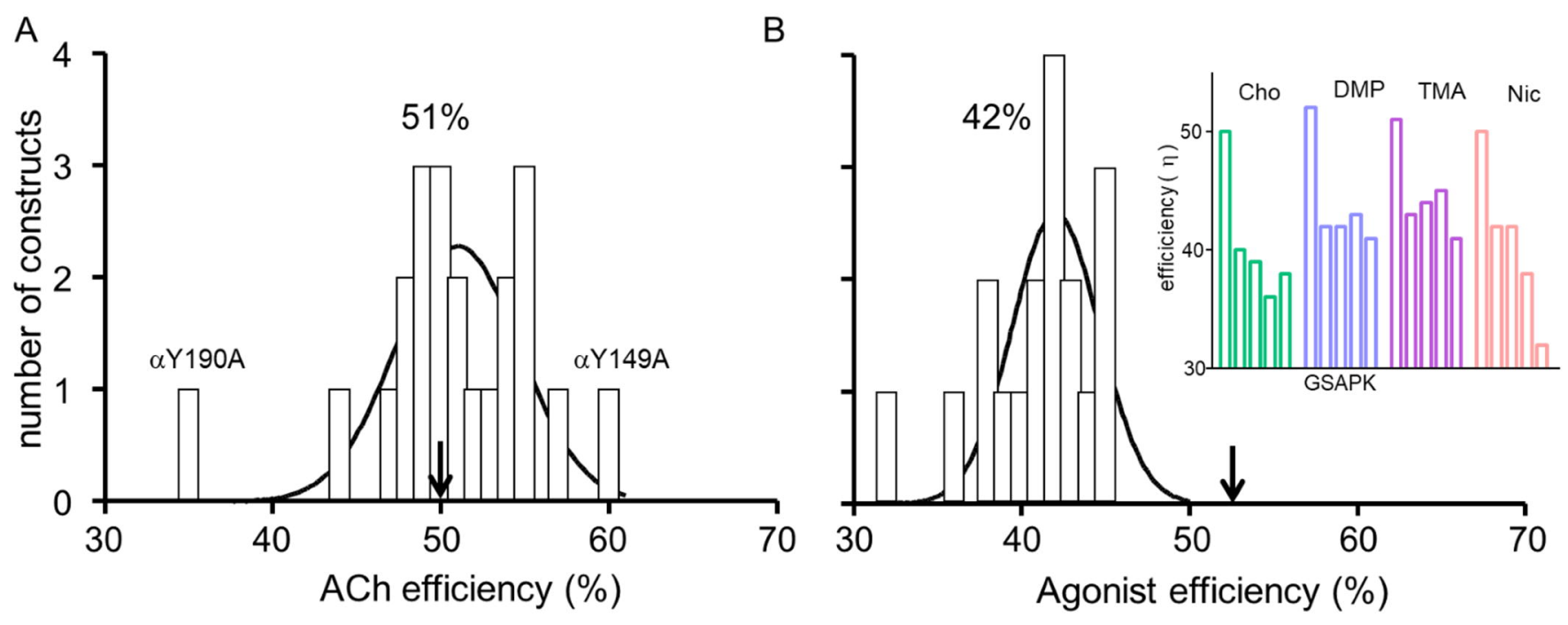
A

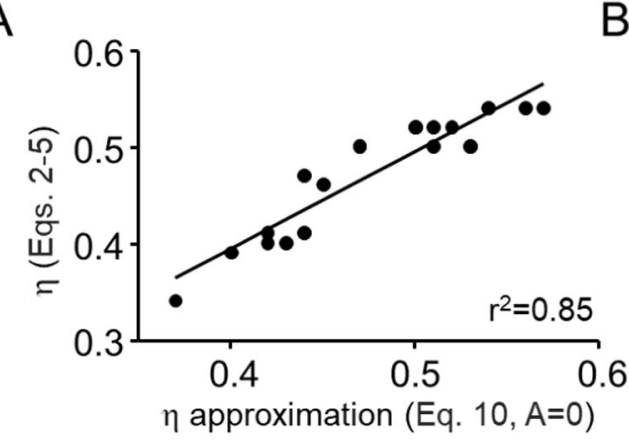

B



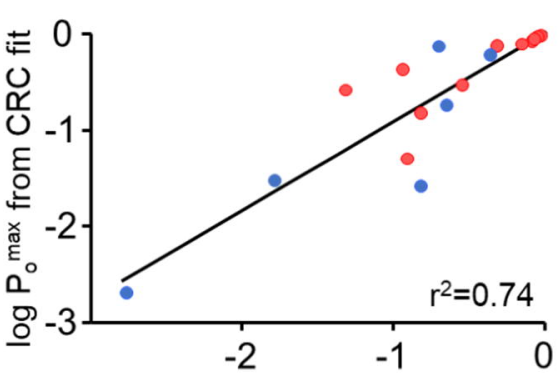

$\log \mathrm{P}_{0}{ }^{\text {max }}$ calculated from $\mathrm{EC}_{50}$

C

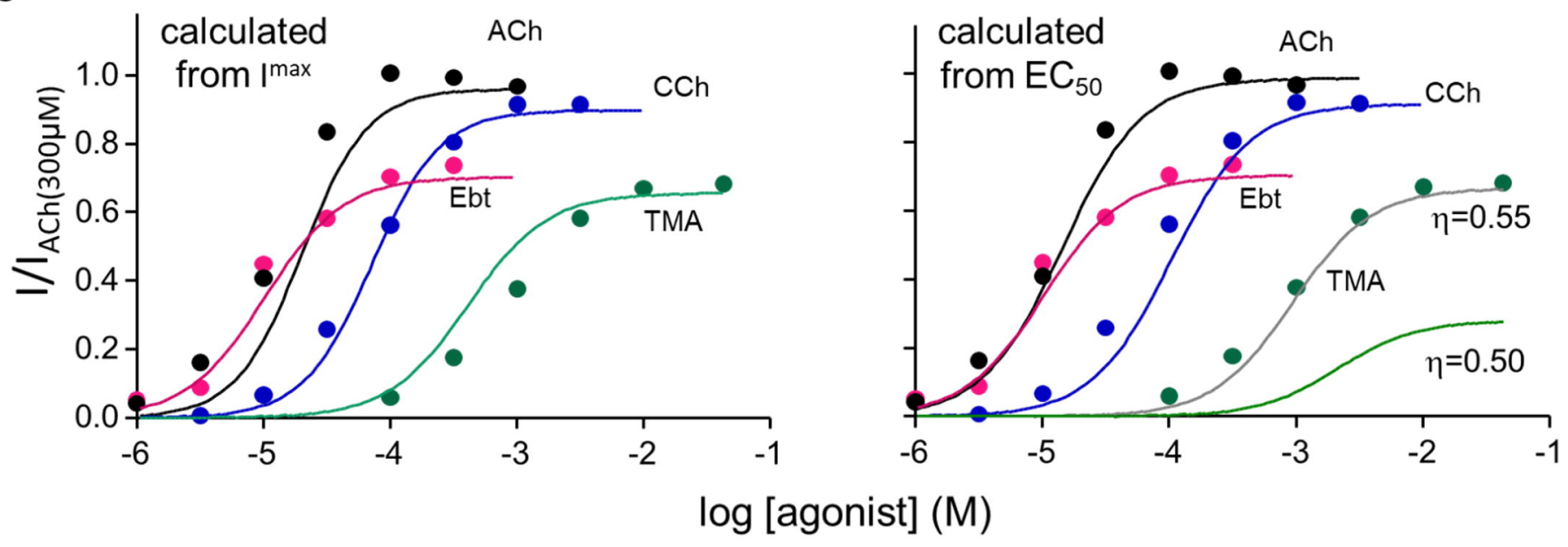

